Review

\title{
Mammalian Introns: When the Junk Generates Molecular Diversity
}

\section{Florent Hubé * and Claire Francastel *}

CNRS UMR7216, Epigenetics and Cell Fate, Université Paris Diderot, Sorbonne Paris Cité, UMR7216 Epigénétique et Destin Cellulaire, Bâtiment Lamarck B, Case Courrier 7042, 35 rue Hélène Brion, 75013 Paris, France

* Authors to whom correspondence should be addressed;

E-Mails: florent.hube@univ-paris-diderot.fr (F.H.); claire.francastel@univ-paris-diderot.fr (C.F.); Tel.: +331-57-27-89-32 (F.H. \& C.F.); Fax: +331-57-27-89-10 (F.H. \& C.F.).

Academic Editor: Akila Mayeda

Received: 16 December 2014 / Accepted: 11 February 2015 / Published: 20 February 2015

\begin{abstract}
Introns represent almost half of the human genome, yet their vast majority is eliminated from eukaryotic transcripts through RNA splicing. Nevertheless, they feature key elements and functions that deserve further interest. At the level of DNA, introns are genomic segments that can shelter independent transcription units for coding and non-coding RNAs which transcription may interfere with that of the host gene, and regulatory elements that can influence gene expression and splicing itself. From the RNA perspective, some introns can be subjected to alternative splicing. Intron retention appear to provide some plasticity to the nature of the protein produced, its distribution in a given cell type and timing of its translation. Intron retention may also serve as a switch to produce coding or non-coding RNAs from the same transcription unit. Conversely, splicing of introns has been directly implicated in the production of small regulatory RNAs. Hence, splicing of introns also appears to provide plasticity to the type of RNA produced from a genetic locus (coding, non-coding, short or long). We addressed these aspects to add to our understanding of mechanisms that control the fate of introns and could be instrumental in regulating genomic output and hence cell fate.
\end{abstract}

Keywords: intron; splicing; genome; gene; non-coding RNA; transcription; data mining 
In eukaryotes, the process of making a messenger RNA (mRNA) involves the co-transcriptional excision of introns in the nucleus, whereas joined-exons are exported to the cytoplasm to be translated. As a consequence, introns are inherently non-protein-coding sequences in that they are transcribed but not translated (usually) into protein. Because, and by definition, introns always lie between 2 exons, they were called "Intervening" or INtrons. By opposition, exons are those sequences that are EXpressed and EXported to the cytoplasm.

\section{Introduction}

In 1993, the Nobel Prize was awarded to Phillip A. Sharp and Richard J. Roberts for their discovery that genes can be split into segments and, as a consequence, transcripts that originate from them are matured into messenger RNA (mRNA) smaller in size. Hence, introns are segments of a gene between exons, which are transcribed but do not participate in the production of the final protein product as they are removed before translation, allowing joining of exons through a process known as splicing. With the discovery that various combinations of segments may be included in the final RNA molecule, this has changed our view on how genetic information is expressed and provided, a posteriori, an explanation on how eukaryotes diversify their proteome from just a few genes. We now know that the fate of introns is not simply a matter of being eliminated to allow formation of mRNA coding for proteins.

Introns are classified in four groups based on splicing mechanisms. (1) Spliceosomal introns are found in coding genes of eukaryotes and utilize spliceosomes (large protein-RNA complexes) for splicing [1]. These introns share consensus sequences [2] that include the $5^{\prime}$ donor site (MAG|GTRAGT where $\mathrm{M}$ is $\mathrm{A} / \mathrm{C}$ and $\mathrm{R}$ is $\mathrm{A} / \mathrm{G}$ ), the branch point sequence covalently linked to the $5^{\prime}$ end of the intron and formation of a lariat during the splicing process of this type of intron (TCCTRAY where $\mathrm{R}$ is $\mathrm{A} / \mathrm{G}$ and $\mathrm{Y}$ is $\mathrm{T} / \mathrm{C}$, A being the branch point nucleotide), the polypyrimidine tract (CnTn) and the 3' acceptor site (MAG|G); (2) Transfer RNA (tRNA) introns are removed by specialized enzymes with endoribonuclease and ligase activities [3]; (3) Group I and (4) Group II introns catalyze their own splicing without the aid of any protein, and where thus named ribozymes [4]. They are found in bacteria, plants and lower but not higher eukaryotes.

Splicing of both Group II and pre-mRNA introns involve the formation of a lariat suggesting that they may be evolutionary related. However, origin and evolution of spliceosomal introns is still a matter of debate, opposing "introns early" to "introns late" theories [5], the main dilemma being on the possible roles of introns in the evolution of eukaryotes.

Being eliminated to allow formation of messenger RNA and inherently non-coding, introns have long been kept in the now famous "junk DNA" drawer. However, and maybe against all odds, high sequence conservation among homologous introns of closely related species suggests functional constraints on intronic sequences throughout evolution [6]. Many studies have now added to the weight of evidence showing that introns can serve a considerable range of biological functions.

We review here aspects of introns that are perhaps less known but made them see a renewed interest lately. 


\section{Introns Account for Half of the Genome-From a Single Nucleotide to One Megabase}

Most eukaryotic genes are interrupted by stretches of non-coding segments, i.e., introns, which cover more than 1.7 billion bases pairs and represent $45 \%$ to $55 \%$ of the human genome (GCRh38, Table 1).

Most introns are above 60-70 base pairs in length as shown in Figure 1. Strikingly, some introns are very small, with about $722(0.25 \%)$ of them being smaller than 73 bases, however, the extremely small introns, especially $\leq 21 \mathrm{nt}$, could reflects false introns, or artifactual gaps, generated by automatic alignments. Thus far, the smallest real intron whose splicing was demonstrated is $43 \mathrm{nt}$ in human ESRP2 gene [7]. In contrast, the longest intron is greater than one megabase (1,043,910 bases) in length, e.g., intron 1 of acid-sensing ion channel 2 (ASIC2; chr17:33,112,068-34,155,977), although this is exceptional since only 35 introns are above $500 \mathrm{~kb}$. Altogether, the average size of introns within coding genes is $5889 \pm 19,584$ bases (median size of 1520) while introns of non-coding genes are slightly longer, with $7793 \pm 23,410$ bases (median size of 1707).

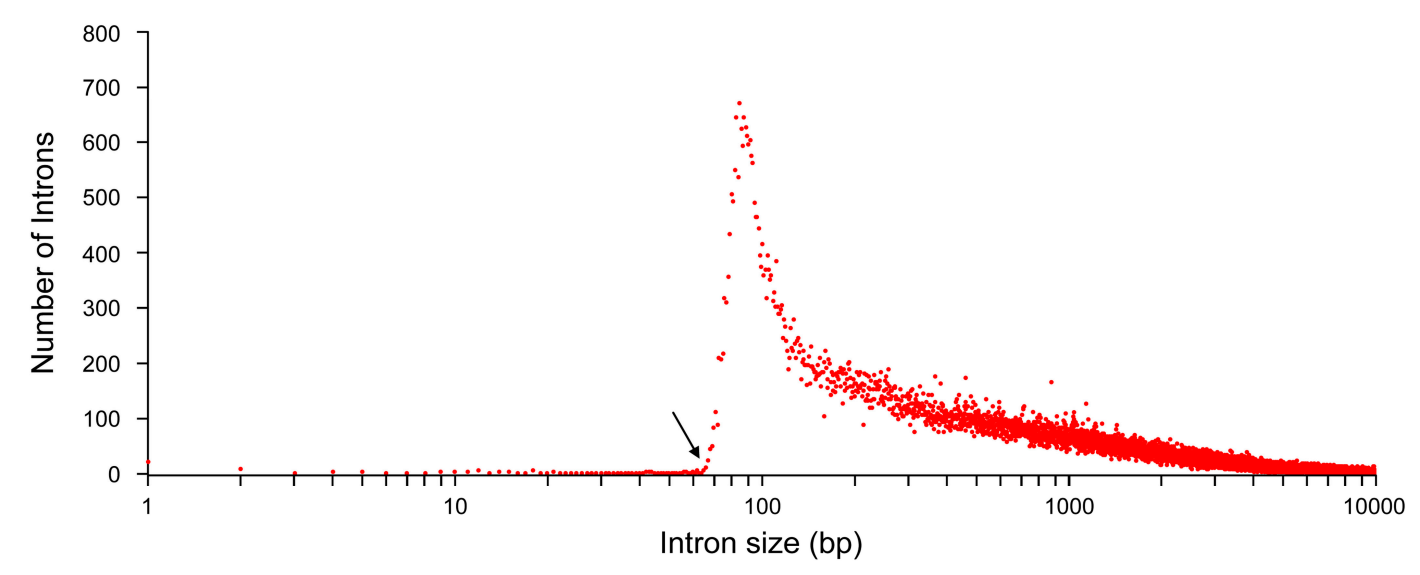

Figure 1. Size distribution of human introns. The human genome data was downloaded from the UCSC main table browser (GRCh38, December 2013 build). Data was processed using tabular software. Analysis was performed using 277,495 introns. The lower size limit for human introns is represented by the dark arrow and is comprised between 60 and 70 bases.

Surprisingly, 1394 coding genes (5.33\% of total annotated coding sequences, Table 2) and 3303 non-coding genes (38.06\% of total annotated non-coding sequences, Table 3 ) are made of a single exon (single-exon genes; SEG), i.e., they are not interrupted by introns. Although intronless genes are an archetypal feature of prokaryotes, significant amounts of SEG are present in the human genome [8]. Whether SEG are of bacterial origin or came through evolutionary innovations such as retrogenes is still open to discussion [9-11]. Interestingly, the high proportion of SEG among non-coding genes would rather be indicative of an evolution from retrotransposons or from ancestral intronless coding genes. 
Table 1. Distribution of exons and introns across human chromosomes. Human genome dataset was downloaded from the UCSC main table browser (GCRh38, December 2013 build). Data was processed using tabular software. Analysis was performed using the 34,856 genes containing 312,351 exons and 277,495 introns. Caution: introns with the length $<30-40 \mathrm{nt}$ likely reflect artifact or error (see text).

\begin{tabular}{|c|c|c|c|c|c|c|c|c|c|c|c|c|c|c|c|c|c|c|}
\hline \multirow{2}{*}{$\begin{array}{c}\text { Chr } \\
\#\end{array}$} & \multirow{2}{*}{$\begin{array}{l}\text { Total \# } \\
\text { Genes }\end{array}$} & \multirow{2}{*}{$\begin{array}{l}\text { Total \# } \\
\text { Exons }\end{array}$} & \multirow{2}{*}{$\begin{array}{l}\text { Total \# } \\
\text { Introns }\end{array}$} & \multirow{2}{*}{$\begin{array}{c}\text { Max \# } \\
\text { Exons/ } \\
\text { Gene }\end{array}$} & \multirow{2}{*}{$\begin{array}{c}\text { Chromosome } \\
\text { Size (bp) }\end{array}$} & \multirow{2}{*}{$\begin{array}{c}\text { Avg \# of } \\
\text { Exons/Gene }\end{array}$} & \multicolumn{2}{|c|}{ Avg Length $(\mathbf{b p}) \pm$ Std Dev } & \multicolumn{2}{|c|}{ Total Length (bp) } & \multicolumn{3}{|c|}{ Shortest (bp) } & \multicolumn{3}{|c|}{ Longest (bp) } & \multirow{2}{*}{$\begin{array}{l}\text { Genes/ } \\
\text { Millions }\end{array}$} & \multirow{2}{*}{$\begin{array}{c}\text { Intronless } \\
\text { Genes }\end{array}$} \\
\hline & & & & & & & Exon & Intron & Exon & Intron & Exon & Intron & Gene & Exon & Intron & Gene & & \\
\hline 1 & 3592 & 31,744 & 28,152 & 138 & $248,956,422$ & 8.8 & $313 \pm 705$ & $5283 \pm 16,017$ & $9,934,447$ & $148,725,908$ & 3 & 1 & 41 & 12,573 & 451,448 & $1,491,100$ & 14.4 & 544 \\
\hline 2 & 2208 & 24,805 & 22,597 & 363 & $242,193,529$ & 11.2 & $299 \pm 718$ & $6574 \pm 21,058$ & $7,407,514$ & $147,572,357$ & 1 & 14 & 49 & 17,969 & 866,400 & $1,900,275$ & 9.1 & 203 \\
\hline 3 & 1916 & 18,292 & 16,376 & 118 & $198,295,559$ & 9.5 & $317 \pm 759$ & $7669 \pm 25,134$ & $5,801,464$ & $125,580,914$ & 3 & 1 & 21 & 24,927 & 842,378 & $1,502,150$ & 9.7 & 181 \\
\hline 4 & 1234 & 10,880 & 9646 & 84 & $190,214,555$ & 8.8 & $343 \pm 740$ & $8687 \pm 26,112$ & $3,736,564$ & $83,794,301$ & 8 & 1 & 44 & 9856 & 912,253 & $1,474,687$ & 6.5 & 197 \\
\hline 5 & 1496 & 13,193 & 11,697 & 90 & $181,538,259$ & 8.8 & $342 \pm 778$ & $7678 \pm 23,233$ & $4,508,195$ & $89,805,936$ & 6 & 12 & 43 & 22,753 & 772,519 & $1,519,058$ & 8.2 & 205 \\
\hline 6 & 1793 & 16,106 & 14,313 & 146 & $170,805,979$ & 9.0 & $326 \pm 719$ & $6876 \pm 20,012$ & $5,256,442$ & $98,421,513$ & 6 & 1 & 50 & 15,177 & 478,750 & $1,987,246$ & 10.5 & 227 \\
\hline 7 & 1629 & 15,280 & 13,651 & 108 & $159,345,973$ & 9.4 & $315 \pm 763$ & $7770 \pm 24,375$ & $4,806,589$ & $106,063,166$ & 2 & 1 & 53 & 21,017 & 657,297 & $2,304,636$ & 10.2 & 187 \\
\hline 8 & 1207 & 10,041 & 8834 & 86 & $145,138,636$ & 8.3 & $335 \pm 779$ & $8354 \pm 26,109$ & $3,363,013$ & $73,802,469$ & 5 & 12 & 23 & 15,980 & 955,098 & $2,059,454$ & 8.3 & 160 \\
\hline 9 & 1402 & 12,839 & 11,437 & 98 & $138,394,717$ & 9.2 & $314 \pm 714$ & $6073 \pm 16,910$ & $4,029,327$ & $69,453,705$ & 3 & 5 & 54 & 10,345 & 344,501 & $2,298,478$ & 10.1 & 200 \\
\hline 10 & 1346 & 12,626 & 11,280 & 68 & $133,797,422$ & 9.4 & $321 \pm 723$ & $7821 \pm 23,764$ & $4,058,525$ & $88,222,345$ & 5 & 67 & 50 & 11,090 & 482,575 & $1,783,674$ & 10.1 & 131 \\
\hline 11 & 2112 & 17,709 & 15,597 & 90 & $135,086,622$ & 8.4 & $311 \pm 959$ & $5306 \pm 20,073$ & $5,501,031$ & $82,757,607$ & 2 & 1 & 50 & 91,671 & 811,152 & $1,468,409$ & 15.6 & 377 \\
\hline 12 & 1773 & 17,618 & 15,845 & 173 & $133,275,309$ & 9.9 & $300 \pm 686$ & $5076 \pm 15,654$ & $5,281,875$ & $80,428,519$ & 9 & 5 & 50 & 14,194 & 403,400 & $1,249,864$ & 13.3 & 169 \\
\hline 13 & 715 & 5982 & 5267 & 83 & $114,364,328$ & 8.4 & $339 \pm 957$ & $9101 \pm 29,323$ & $2,025,232$ & $47,933,871$ & 5 & 66 & 48 & 37,567 & 740,920 & $1,468,616$ & 6.3 & 94 \\
\hline 14 & 1171 & 9771 & 8600 & 116 & $107,043,718$ & 8.3 & $319 \pm 734$ & $6212 \pm 20,436$ & $3,115,048$ & $53,426,644$ & 4 & 14 & 46 & 17,546 & 479,079 & $1,464,560$ & 10.9 & 229 \\
\hline 15 & 1188 & 11,480 & 10,292 & 104 & $101,991,189$ & 9.7 & $306 \pm 698$ & $5672 \pm 17,698$ & $3,514,500$ & $58,372,375$ & 8 & 21 & 33 & 11,532 & 732,200 & 887,042 & 11.6 & 220 \\
\hline 16 & 1468 & 13,212 & 11,744 & 63 & $90,338,345$ & 9.0 & $285 \pm 607$ & $3892 \pm 17,423$ & $3,766,310$ & $45,712,994$ & 3 & 1 & 51 & 10,024 & 778,855 & $1,694,208$ & 16.3 & 159 \\
\hline 17 & 2069 & 19,482 & 17,413 & 85 & $83,257,441$ & 9.4 & $289 \pm 615$ & $3531 \pm 13,106$ & $5,622,686$ & $61,484,756$ & 8 & 1 & 47 & 10,345 & $1,043,910$ & $1,143,719$ & 24.9 & 251 \\
\hline 18 & 495 & 4568 & 4073 & 75 & $80,373,285$ & 9.2 & $362 \pm 850$ & $10,552 \pm 25,422$ & $1,653,586$ & $42,976,591$ & 9 & 75 & 50 & 14,862 & 411,175 & $1,195,732$ & 6.2 & 58 \\
\hline 19 & 2449 & 18,534 & 16,085 & 106 & $58,617,616$ & 7.6 & $297 \pm 655$ & $2382 \pm 6158$ & $5,507,290$ & $38,316,474$ & 6 & 2 & 47 & 21,693 & 255,789 & 301,152 & 41.8 & 358 \\
\hline 20 & 983 & 8035 & 7052 & 80 & $64,444,167$ & 8.2 & $312 \pm 675$ & $5515 \pm 18,323$ & $2,509,662$ & $38,891,514$ & 8 & 31 & 50 & 10,441 & 544,980 & $2,057,697$ & 15.3 & 103 \\
\hline 21 & 463 & 3745 & 3282 & 47 & $46,709,983$ & 8.1 & $309 \pm 728$ & $6401 \pm 18,061$ & $1,157,367$ & $21,006,837$ & 9 & 9 & 60 & 13,351 & 323,564 & 834,698 & 9.9 & 95 \\
\hline 22 & 797 & 7029 & 6232 & 55 & $50,818,468$ & 8.8 & $312 \pm 712$ & $4321 \pm 12,968$ & $2,194,256$ & $26,927,006$ & 4 & 1 & 52 & 12,955 & 355,998 & 701,852 & 15.7 & 84 \\
\hline $\mathbf{x}$ & 1152 & 8062 & 6910 & 84 & $156,040,895$ & 7.0 & $350 \pm 873$ & $6898 \pm 24,018$ & $2,820,104$ & $47,662,441$ & 7 & 67 & 48 & 37,027 & 536,479 & $1,368,337$ & 7.4 & 244 \\
\hline $\mathbf{Y}$ & 198 & 1318 & 1120 & 46 & $57,227,415$ & 6.7 & $259 \pm 540$ & $10,637 \pm 33,468$ & 341,789 & $14,179,080$ & 22 & 67 & 64 & 8690 & 493,512 & 686,139 & 3.5 & 11 \\
\hline
\end{tabular}


Table 2. Exons and introns distribution across human coding genes. Human genome data was downloaded from the UCSC main table browser (GCRh38, December 2013 build). Data was processed using tabular software. Analysis was performed using 26,177 coding genes, containing 278,420 exons and 252,243 introns. See the caution in Table 1 for the shortest introns $(<30-40 \mathrm{nt})$.

\begin{tabular}{|c|c|c|c|c|c|c|c|c|c|c|c|c|c|c|c|c|c|c|}
\hline \multirow{2}{*}{$\begin{array}{c}\text { Chr } \\
\#\end{array}$} & \multirow{2}{*}{$\begin{array}{l}\text { Total \# } \\
\text { Genes }\end{array}$} & \multirow{2}{*}{$\begin{array}{l}\text { Total \# } \\
\text { Exons }\end{array}$} & \multirow{2}{*}{$\begin{array}{l}\text { Total \# } \\
\text { Introns }\end{array}$} & \multirow{2}{*}{$\begin{array}{c}\text { Max \# } \\
\text { Exons/Gene }\end{array}$} & \multirow{2}{*}{$\begin{array}{c}\text { Chromosome } \\
\text { Size (bp) }\end{array}$} & \multirow{2}{*}{$\begin{array}{c}\text { Avg \# of } \\
\text { Exons/Gene }\end{array}$} & \multicolumn{2}{|c|}{ Avg Length $(b p) \pm$ Std Dev } & \multicolumn{2}{|c|}{ Total Length (bp) } & \multicolumn{3}{|c|}{ Shortest (bp) } & \multicolumn{3}{|c|}{ Longest (bp) } & \multirow{2}{*}{$\begin{array}{c}\text { Genes/ } \\
\text { Millions }\end{array}$} & \multirow{2}{*}{$\begin{array}{c}\text { Intronless } \\
\text { Genes }\end{array}$} \\
\hline & & & & & & & Exon & Intron & Exon & Intron & Exon & Intron & Gene & Exon & Intron & Gene & & \\
\hline 1 & 2729 & 28,554 & 25,825 & 138 & $248,956,422$ & 10.5 & $307 \pm 702$ & $5136 \pm 15,685$ & $8,778,766$ & $132,633,451$ & 3 & 1 & 270 & 12,573 & 451,448 & $1,491,100$ & 11.0 & 149 \\
\hline 2 & 1653 & 22,244 & 20,591 & 363 & $242,193,529$ & 13.5 & $294 \pm 723$ & $6283 \pm 20,404$ & $6,534,873$ & $128,437,100$ & 1 & 37 & 582 & 17,969 & 866,400 & $1,900,275$ & 6.8 & 35 \\
\hline 3 & 1448 & 16,336 & 14,888 & 118 & $198,295,559$ & 11.3 & $312 \pm 765$ & $7535 \pm 24,995$ & $5,098,251$ & $5,098,251$ & 3 & 3 & 294 & 24,927 & 24,927 & $1,502,150$ & 7.3 & 44 \\
\hline 4 & 989 & 9991 & 9002 & 84 & $190,214,555$ & 10.1 & $338 \pm 729$ & $8471 \pm 25,955$ & $3,372,765$ & $76,252,775$ & 8 & 1 & 576 & 9856 & 912,253 & $1,474,687$ & 5.2 & 107 \\
\hline 5 & 1103 & 11,709 & 10,606 & 90 & $181,538,259$ & 10.6 & $337 \pm 785$ & $7240 \pm 22,309$ & $3,944,829$ & $76,788,283$ & 6 & 21 & 530 & 22,753 & 772,519 & $1,519,058$ & 6.1 & 85 \\
\hline 6 & 1432 & 14,660 & 13,228 & 146 & $170,805,979$ & 10.2 & $317 \pm 713$ & $6665 \pm 19,530$ & $4,653,325$ & $88,160,529$ & 6 & 1 & 354 & 15,177 & 478,750 & $1,987,246$ & 8.4 & 109 \\
\hline 7 & 1189 & 13,187 & 11,998 & 108 & $159,345,973$ & 11.1 & $306 \pm 744$ & $7897 \pm 24,804$ & $4,032,145$ & $94,745,609$ & 2 & 1 & 600 & 14,889 & 657,297 & $2,304,636$ & 7.5 & 55 \\
\hline 8 & 869 & 8779 & 7910 & 86 & $145,138,636$ & 10.1 & $327 \pm 768$ & $7942 \pm 24,970$ & $2,871,568$ & $62,820,216$ & 5 & 12 & 663 & 15,980 & 955,098 & $2,059,454$ & 6.0 & 26 \\
\hline 9 & 1041 & 11,352 & 10,311 & 98 & $138,394,717$ & 10.9 & $304 \pm 703$ & $5971 \pm 16,684$ & $3,453,046$ & $61,566,944$ & 3 & 5 & 411 & 10,345 & 344,501 & $2,298,478$ & 7.5 & 73 \\
\hline 10 & 978 & 11,096 & 10,118 & 68 & $133,797,422$ & 11.3 & $310 \pm 715$ & $7926 \pm 24,491$ & $3,440,785$ & $80,199,711$ & 5 & 67 & 563 & 11,090 & 482,575 & $1,783,674$ & 7.3 & 26 \\
\hline 11 & 1703 & 16,196 & 14,493 & 90 & $135,086,622$ & 9.5 & $301 \pm 665$ & $5136 \pm 19,917$ & $4,880,180$ & $74,431,941$ & 2 & 1 & 484 & 18,173 & 811,152 & $1,468,409$ & 12.6 & 211 \\
\hline 12 & 1407 & 16,186 & 14,779 & 173 & $133,275,309$ & 11.5 & $294 \pm 688$ & $4939 \pm 15,284$ & $4,757,204$ & $72,993,897$ & 9 & 5 & 396 & 14,194 & 403,400 & $1,249,864$ & 10.6 & 50 \\
\hline 13 & 426 & 4920 & 4494 & 83 & $114,364,328$ & 11.5 & $330 \pm 864$ & $8615 \pm 29,149$ & $1,624,165$ & $38,717,496$ & 5 & 66 & 1310 & 21,022 & 740,920 & $1,468,616$ & 3.7 & 10 \\
\hline 14 & 832 & 8745 & 7913 & 116 & $107,043,718$ & 10.5 & $319 \pm 741$ & $6107 \pm 20,447$ & $2,786,125$ & $48,327,558$ & 4 & 14 & 465 & 17,546 & 479,079 & $1,464,560$ & 7.8 & 38 \\
\hline 15 & 769 & 9686 & 8917 & 104 & $101,991,189$ & 12.6 & $299 \pm 689$ & $5508 \pm 16,227$ & $2,900,248$ & $49,116,901$ & 8 & 21 & 918 & 10,227 & 550,366 & 887,042 & 7.5 & 23 \\
\hline 16 & 1117 & 11,738 & 10,621 & 63 & $90,338,345$ & 10.5 & $281 \pm 607$ & $3831 \pm 17,251$ & $3,296,823$ & $40,686,903$ & 5 & 1 & 397 & 10,024 & 778,855 & $1,694,208$ & 12.4 & 20 \\
\hline 17 & 1619 & 17,644 & 16,025 & 85 & $83,257,441$ & 10.9 & $280 \pm 605$ & $3427 \pm 13,031$ & $4,943,096$ & $54,914,295$ & 8 & 1 & 445 & 9719 & $1,043,910$ & $1,143,719$ & 19.4 & 68 \\
\hline 18 & 364 & 4082 & 3718 & 75 & $80,373,285$ & 11.2 & $360 \pm 872$ & $10,356 \pm 24,257$ & $1,469,520$ & $38,504,335$ & 9 & 75 & 906 & 14,862 & 411,175 & $1,195,732$ & 4.5 & 17 \\
\hline 19 & 1904 & 16,757 & 14,853 & 106 & $58,617,616$ & 8.8 & $296 \pm 659$ & $2283 \pm 5233$ & $4,964,098$ & $33,906,702$ & 6 & 2 & 541 & 21,693 & 121,730 & 301,152 & 32.5 & 54 \\
\hline 20 & 741 & 7114 & 6373 & 80 & $64,444,167$ & 9.6 & $307 \pm 669$ & $5564 \pm 18,912$ & $2,180,506$ & $35,459,411$ & 11 & 66 & 666 & 10,441 & 544,980 & $2,057,697$ & 11.5 & 23 \\
\hline 21 & 311 & 3183 & 2872 & 47 & $46,709,983$ & 10.2 & $292 \pm 700$ & $5831 \pm 16,574$ & 930,502 & $16,745,676$ & 9 & 9 & 147 & 11,938 & 323,564 & 834,698 & 6.7 & 54 \\
\hline 22 & 598 & 6190 & 5592 & 55 & $50,818,468$ & 10.4 & $300 \pm 702$ & $4156 \pm 11,646$ & $1,857,403$ & $23,242,726$ & 8 & 1 & 686 & 12,955 & 322,908 & 701,852 & 11.8 & 14 \\
\hline $\mathbf{x}$ & 854 & 7222 & 6368 & 84 & $156,040,895$ & 8.5 & $344 \pm 774$ & $6428 \pm 22,011$ & $2,483,142$ & $40,934,557$ & 10 & 67 & 501 & 10,363 & 536,479 & $1,368,337$ & 5.5 & 79 \\
\hline $\mathbf{Y}$ & 101 & 849 & 748 & 46 & $57,227,415$ & 8.4 & $267 \pm 576$ & $9483 \pm 32,196$ & 226,383 & $5,888,994$ & 24 & 67 & 737 & 8690 & 493,512 & 686,139 & 1.8 & 9 \\
\hline
\end{tabular}


Table 3. Exons and introns distribution across human non-coding genes. Human genome data was downloaded from the UCSC main table browser (GCRh38, December 2013 build). Data was processed using tabular software. Analysis was performed using 8679 non-coding genes containing 33,931 exons and 25,252 introns. See the caution in Table 1 for the shortest introns $(<30-40 \mathrm{nt})$.

\begin{tabular}{|c|c|c|c|c|c|c|c|c|c|c|c|c|c|c|c|c|c|c|}
\hline \multirow{2}{*}{$\begin{array}{c}\text { Chr } \\
\# \\
\end{array}$} & \multirow{2}{*}{$\begin{array}{l}\text { Total \# } \\
\text { Genes } \\
\end{array}$} & \multirow{2}{*}{$\begin{array}{l}\text { Total \# } \\
\text { Exons }\end{array}$} & \multirow{2}{*}{$\begin{array}{l}\text { Total \# } \\
\text { Introns }\end{array}$} & \multirow{2}{*}{$\begin{array}{c}\text { Max \# } \\
\text { Exons/Gene }\end{array}$} & \multirow{2}{*}{$\begin{array}{c}\text { Chromosome } \\
\text { Size (bp) } \\
\end{array}$} & \multirow{2}{*}{$\begin{array}{c}\text { Avg \# of } \\
\text { Exons/Gene }\end{array}$} & \multicolumn{2}{|c|}{ Avg length (bp) \pm Std Dev } & \multicolumn{2}{|c|}{ Total length (bp) } & \multicolumn{3}{|c|}{ Shortest (bp) } & \multicolumn{3}{|c|}{ Longest (bp) } & \multirow{2}{*}{$\begin{array}{c}\text { Genes/ } \\
\text { Millions } \\
\end{array}$} & \multirow{2}{*}{$\begin{array}{c}\text { Intronless } \\
\text { Genes } \\
\end{array}$} \\
\hline & & & & & & & Exon & Intron & Exon & Intron & Exon & Intron & Gene & Exon & Intron & Gene & & \\
\hline 1 & 863 & 3190 & 2327 & 46 & $248,956,422$ & 3.7 & $362 \pm 731$ & $6916 \pm 19,245$ & $1,155,681$ & $16,092,457$ & 4 & 44 & 41 & 11,846 & 300,899 & 670,478 & 3.5 & 395 \\
\hline 2 & 555 & 2561 & 2006 & 55 & $242,193,529$ & 4.6 & $341 \pm 668$ & $9539 \pm 26,653$ & 872,641 & $19,135,257$ & 3 & 14 & 49 & 11,633 & 415,325 & $1,126,123$ & 2.3 & 168 \\
\hline 3 & 468 & 1956 & 1488 & 45 & $198,295,559$ & 4.2 & $360 \pm 702$ & $9009 \pm 26,455$ & 703,213 & $13,405,364$ & 12 & 67 & 21 & 8244 & 427,004 & 581,065 & 2.4 & 137 \\
\hline 4 & 245 & 889 & 644 & 36 & $190,214,555$ & 3.6 & $409 \pm 847$ & $11,710 \pm 28,055$ & 363,799 & $7,541,526$ & 12 & 60 & 44 & 9848 & 250,403 & 491,647 & 1.3 & 90 \\
\hline 5 & 393 & 1484 & 1091 & 30 & $181,538,259$ & 3,8 & $380 \pm 722$ & $11,932 \pm 30,494$ & 563,366 & $13,017,653$ & 15 & 12 & 43 & 8875 & 340,222 & 932,203 & 2.2 & 120 \\
\hline 6 & 361 & 1446 & 1085 & 36 & $170,805,979$ & 4.0 & $417 \pm 772$ & $9457 \pm 25,027$ & 603,117 & $10,260,984$ & 7 & 73 & 50 & 8695 & 326,934 & 621,277 & 2.1 & 118 \\
\hline 7 & 440 & 2093 & 1653 & 48 & $159,345,973$ & 4.8 & $370 \pm 871$ & $6847 \pm 20,981$ & 774,444 & $11,317,557$ & 13 & 70 & 53 & 21,017 & 414,132 & 630,440 & 2.8 & 132 \\
\hline 8 & 338 & 1262 & 924 & 29 & $145,138,636$ & 3.7 & $389 \pm 844$ & $11,886 \pm 34,163$ & 491,445 & $10,982,253$ & 15 & 71 & 23 & 12,722 & 499,303 & 541,308 & 2.3 & 134 \\
\hline 9 & 361 & 1487 & 1126 & 45 & $138,394,717$ & 4.1 & $388 \pm 791$ & $7004 \pm 18,841$ & 576,281 & $7,886,761$ & 14 & 68 & 54 & 7835 & 308,685 & 310,090 & 2.6 & 127 \\
\hline 10 & 368 & 1530 & 1162 & 28 & $133,797,422$ & 4.2 & $404 \pm 776$ & $6904 \pm 16,076$ & 617,740 & $8,022,634$ & 15 & 73 & 50 & 7617 & 212,605 & 337,030 & 2.8 & 105 \\
\hline 11 & 409 & 1513 & 1104 & 29 & $135,086,622$ & 3.7 & $410 \pm 2455$ & $7541 \pm 21,908$ & 620,851 & $8,325,666$ & 5 & 44 & 50 & 91,671 & 295,436 & 663,821 & 3.0 & 166 \\
\hline 12 & 366 & 1432 & 1066 & 27 & $133,275,309$ & 3.9 & $366 \pm 666$ & $6974 \pm 19,998$ & 524,671 & $7,434,622$ & 17 & 15 & 50 & 10,432 & 266,879 & 373,979 & 2.7 & 119 \\
\hline 13 & 289 & 1062 & 773 & 26 & $114,364,328$ & 3.7 & $378 \pm 1306$ & $11,923 \pm 30,179$ & 401,067 & $9,216,375$ & 14 & 76 & 48 & 37,567 & 330,963 & 562,471 & 2.5 & 84 \\
\hline 14 & 339 & 1026 & 687 & 46 & $107,043,718$ & 3.0 & $321 \pm 679$ & $7422 \pm 20,278$ & 328,923 & $5,099,086$ & 23 & 76 & 46 & 8430 & 289,502 & 437,743 & 3.2 & 191 \\
\hline 15 & 419 & 1794 & 1375 & 35 & $101,991,189$ & 4.3 & $342 \pm 742$ & $6731 \pm 25,217$ & 614,252 & $9,255,474$ & 10 & 21 & 33 & 11,532 & 732,200 & 797,140 & 4.1 & 197 \\
\hline 16 & 351 & 1474 & 1123 & 50 & $90,338,345$ & 4.2 & $319 \pm 601$ & $4476 \pm 18,977$ & 469,487 & $5,026,091$ & 3 & 47 & 51 & 7148 & 368,335 & 531,096 & 3.9 & 139 \\
\hline 17 & 450 & 1838 & 1388 & 61 & $83,257,441$ & 4.1 & $370 \pm 699$ & $4734 \pm 13,885$ & 679,590 & $6,570,461$ & 15 & 70 & 47 & 10,345 & 220,687 & 325,488 & 5.4 & 183 \\
\hline 18 & 131 & 486 & 355 & 22 & $80,373,285$ & 3.7 & $379 \pm 642$ & $12,598 \pm 35,371$ & 184,066 & $4,472,256$ & 26 & 89 & 50 & 4791 & 326,668 & 545,072 & 1.6 & 41 \\
\hline 19 & 545 & 1777 & 1232 & 30 & $58,617,616$ & 3.3 & $306 \pm 611$ & $3579 \pm 12,785$ & 543,192 & $4,409,772$ & 11 & 62 & 47 & 11,194 & 255,789 & 292,306 & 9.3 & 304 \\
\hline 20 & 242 & 921 & 679 & 43 & $64,444,167$ & 3.8 & $357 \pm 720$ & $5055 \pm 11,393$ & 329,156 & $3,432,103$ & 8 & 31 & 50 & 10,441 & 138,007 & 195,695 & 3.8 & 80 \\
\hline 21 & 152 & 562 & 410 & 32 & $46,709,983$ & 3.7 & $404 \pm 869$ & $10,393 \pm 25,888$ & 226,865 & $4,261,161$ & 16 & 79 & 60 & 13,351 & 256,374 & 539,254 & 3.3 & 41 \\
\hline 22 & 199 & 839 & 640 & 30 & $50,818,468$ & 4.2 & $401 \pm 775$ & $5757 \pm 21,234$ & 336,853 & $3,684,280$ & 4 & 9 & 52 & 8320 & 355,998 & 411,958 & 3.9 & 70 \\
\hline $\mathbf{x}$ & 298 & 840 & 542 & 17 & $156,040,895$ & 2.8 & $401 \pm 1472$ & $12,413 \pm 40,403$ & 336,962 & $6,727,884$ & 7 & 78 & 48 & 37,027 & 405,107 & $1,033,350$ & 1.9 & 165 \\
\hline $\mathbf{Y}$ & 97 & 469 & 372 & 26 & $57,227,415$ & 4.8 & $246 \pm 467$ & $16,221 \pm 58,381$ & 115,406 & $1,313,894$ & 22 & 90 & 64 & 5836 & 353,508 & 320,464 & 1.7 & 2 \\
\hline
\end{tabular}


In contrast to abundant intronless genes, coding and non-coding genes rarely contain more than 100 or 50 exons respectively (15 coding and 7 non-coding genes). The absolute record is held by the titin gene, which contains 363 exons (TTN; chr2:178,525,990-178,807,423). However, overall, a typical coding gene contains 10.8 exons and 9.8 introns (Table 2). In contrast, non-coding genes appear to contain 3.9 exons and 2.9 introns on average (Table 3 ).

\section{Introns May Contain Independent Coding and Non-Coding Genes}

Gene distribution in the human genome is not uniform, some regions being free of genes and others where genes are closely packed. In some cases nearby genes can even overlap. A peculiar case of overlapping genes are nested genes, i.e., independent transcription units entirely included within the bounds of an intron, or more rarely of an exon, of a larger gene (reviewed in [12]). About 10\% of Drosophila melanogaster genes [13], but only $1 \%$ (373) of human genes [14], were assigned to nested positions, two-thirds of them being transcribed from the strand opposite to that of their host gene. About $58 \%$ of the nested/host pairs were conserved in the mouse and some were even present in chicken and fish, while nested pseudogenes are only poorly conserved [14]. The majority of these nested genes code for proteins that are functionally unrelated to that encoded by their host genes [14].

Nested genes that produce small regulatory RNAs independently of the transcription of the host gene have also been described [12,14]. Examples of coding and non-coding nested genes are illustrated in Figure 2. With respect to miRNA genes, independent transcription units account for about 350 miRNA genes (about half of all intronic miRNAs which themselves account for about half of total miRNAs in the human genome; miRBase release 17.0). These intronic miRNAs under the control of their own promoter have to be distinguished from other intronic miRNAs whose production is strictly dependent on transcription of the host gene (see Section 6. below) and from so-called mirtrons or most of the snoRNAs that rely on splicing of the host mRNA to be produced (see below) [15-17]. Intriguingly, at least one miRNA, miRNA-128-2, can be expressed from two different promoters and by two different polymerases (Pol II and Pol III) $[18,19]$. Among the other small ncRNAs, transfert RNAs (tRNAs) can also be hosted in other genes. In the human genome, out of the 497 tRNA genes and 324 tRNA-derived pseudogenes supposed to be no longer functional, 47 (about 10\%) were located in intron of coding genes and 32 (about 10\%) in intron of non-coding genes (hg19). For example, the tRNA-Leu (anticodon TAA; chr6:69,204,486-69,204,568) is located in the intron 17 of the human brain-specific angiogenesis inhibitor 3 (BAI3; chr6:69,232,406-69,389,511) gene.

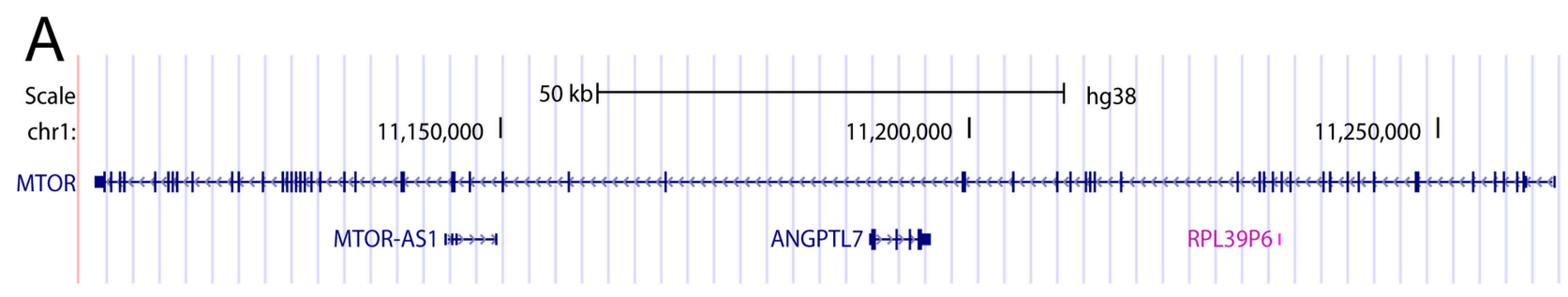

Figure 2. Cont. 


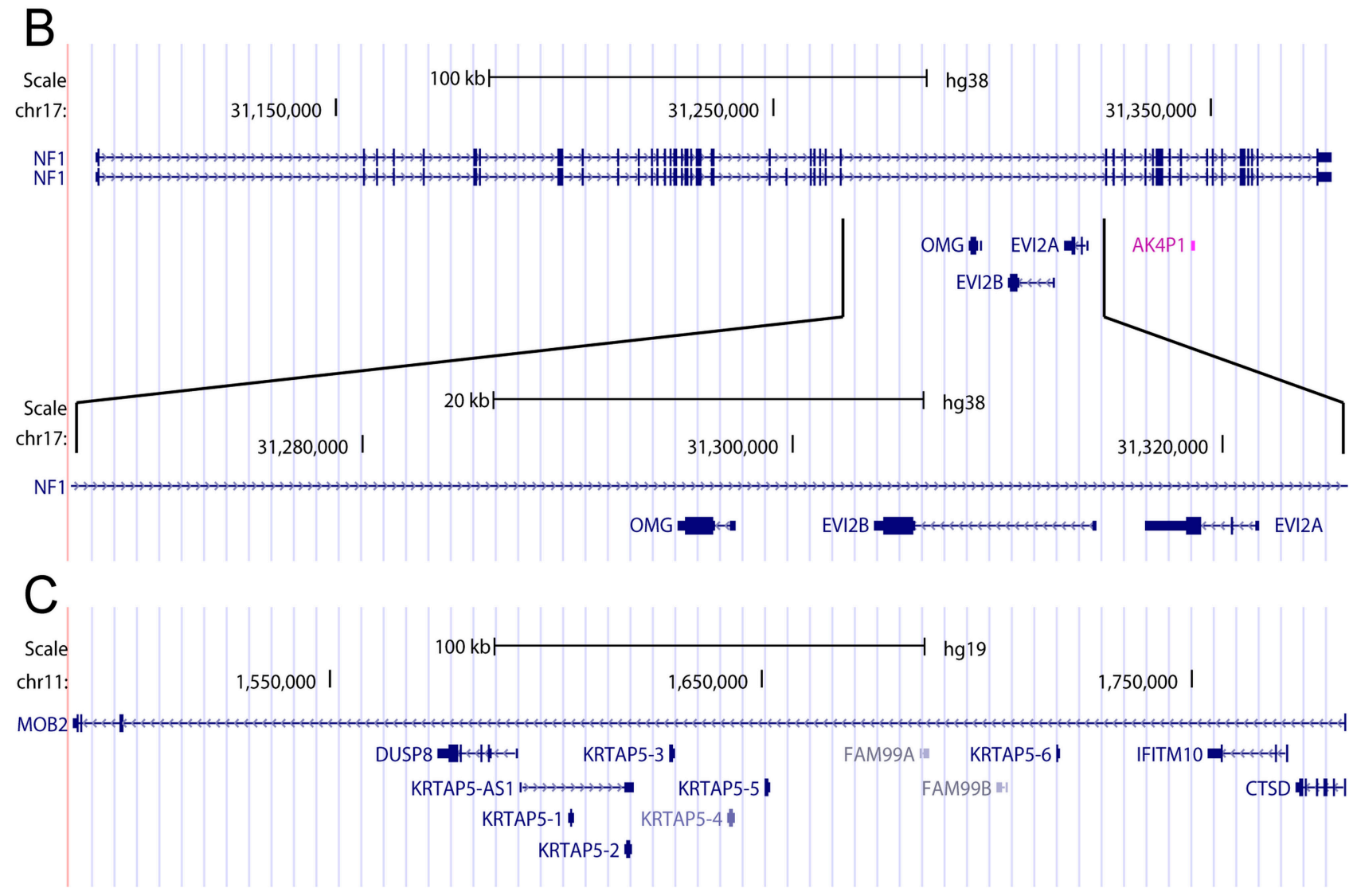

Figure 2. Selected tracks for the human MTOR (A); $N F 1$ (B) and $M O B 2$ (C) genes. (A) Mechanistic target of rapamycin (serine/threonine kinase) gene (MTOR; chr1:11,166,588-11,322,608) is composed of 58 exons spanning 156,020 nucleotides. It contains 3 nested genes: MTOR-AS1 (MTOR antisense RNA 1; chr1:11,203, 955-11,209,595) gene which encodes an antisense RNA across introns 24 to 27 and overlapping exon 25; ANGPTL7 (chr1:11,249,346-11,256,038) gene embedded in intron 30; RPL39P6 (chr1:11,293,020-11,293,169) gene which is a pseudogene included in intron 43; (B) Neurofibromin 1 gene (NF1; chr17:29,421,945-29,704,695) composed of 58 exons spanning 282,751 nucleotides holds 4 nested genes, 3 of which are coding genes located in intron 30 and 1 is a pseudogene ( $A K 4 P 1$; chr17:29,672,539-29,673,205; included in intron 42), all of which are transcribed from the opposite strand. The 3 nested genes are the oligodendrocyte myelin glycoprotein gene (OMG; chr17:29,621, 668-29,624,380), ecotropic viral integration site 2A (EVI2A; chr17:29,643,428-29,648,767) and 2B (EVI2B; chr17:29,630,788-29,641,130); (C) MOB kinase activator 2 gene (MOB2; chr11:1,490,685-1,785,501) contains 13 nested genes: dual specificity phosphatase 8 (DUSP8) coding gene; KRTAP5-1/KRTAP5-2 antisense RNA 1 (KRTAP5-AS1) pseudogene; keratin associated protein 5-1 (KRTAP5-1) and 5 other paralog genes (KRTAP5-2 to -6); family with sequence similarity 99, member A (FAM99A) and member B $(F A M 99 B)$ which are non-coding genes; interferon induced transmembrane protein 10 (IFITM10) and cathepsin D (CTSD) coding genes; one unannotated gene corresponding to EST GenBank AF085962. Amazingly, KRTAP5-1 gene was embedded within and oriented in the opposite direction of KRTAP5-AS1 pseudogene intron, itself oriented in the opposite direction to MOB2 intron. 
Although it has been proposed that a compact genome allows for quicker replication rate in prokaryotes, the functional benefits for mammalian genomes to hold nested genes are still unclear. Still, the presence of nested transcription units in introns raises the questions of their concerted transcription and regulation. It is likely that the host gene and its nested gene transcribed from the opposite strand are inversely regulated and transcribed, owing to promoter competition or steric hindrance of RNA polymerase and transcription factors. In contrast, if the nested and host genes are transcribed from the same strand, it is quite straightforward to predict a concerted model of transcriptional regulation of both genes to allow expression, if not in the same pathways, at least in the same cellular context or in response to the same environmental cues.

\section{When Introns Are too Big to Be Spliced at Once-Intron Re-Splicing}

Through classical mechanisms than we will not detail here, pre-mRNA splicing is precisely controlled in a spatial and temporal manner to generate mature RNAs (For a review, see [20]). If one can easily understand the mechanisms by which "normal" introns (100-1000 nucleotides) are excised, it is more difficult to visualize the case of long or very long introns, in particular when it involves the formation of a lariat as this is the case for spliceosomal introns. In fact, a multi-step process called re-splicing has been proposed for some of these huge introns, along which long introns are removed in successive reactions. Besides canonical splicing (Figure 3A), at least two additional pathways have been described to date (Figure 3B,C):

(1) The recursive splicing consists in the stepwise removal of introns by sequential splicing reactions starting from the most 5 ' donor site and progressing towards the most 3 ' acceptor site $[21,22]$. To date, recursive splicing has not been found in vertebrate cells. The most studied recursive splicing process is that of the ultrabithorax (Ubx) gene in the fruit fly.

(2) The intra-splicing or nested splicing first requires internal splicing, using internal canonical donor and acceptor sites, followed by external splicing involving the most outer donor and acceptor sites [23]. This process thus involves multiple splicing events within a large intron, to shorten it and bring it to a size that can be handled by conventional splicing machineries and mechanisms. To our knowledge, these splicing events, despite the fact that each of them represents an intermediate step in the entire process, do not have particular characteristics that make them distinguishable from classical splicing mechanisms. Ribonucleoprotein complexes seem to be identical between nested and canonical splicing and they both involve the formation of intermediate lariat structures.

The human dystrophin gene (DMD; chrX:31,137,345-33,357,726) is one of the largest annotated genes, spanning more than $2 \mathrm{Mbp}$ and generating transcripts containing up to 79 coding exons. Strikingly, $D M D$ transcripts are only $14 \mathrm{~kb}$ long since more than $99 \%$ of the gene sequence is composed of introns, whose lengths vary from $107 \mathrm{nt}$ (intron 14) to 248,401 nt (intron 44) [23]. Intron 7 (chrX:32,717,411-32,827,609) of the Dp427c isoform (NM_000109) is spliced out through an intrasplicing mechanism [24]. Another example is the erythrocyte Membrane Protein Band 4.1 (EPB41) gene in which Exon 1A and exon 2 are joined through two nested splicing events [25]. 


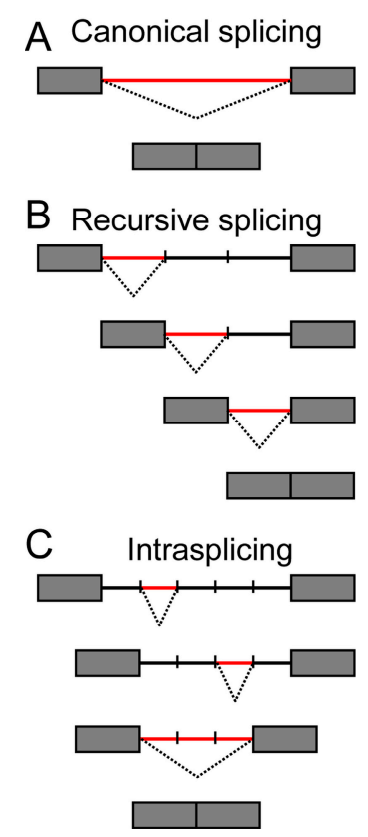

Figure 3. Schematic representation of canonical- (A), recursive- (B), and intra- (C) splicing. Boxes and lines are exons and introns, respectively. Splicing processes are shown by dotted lines.

\section{Cytoplasmic Splicing-Adding to the Complexity of Transcriptional Regulation}

In eukaryotes, splicing occurs in the nucleus in a transcription-coupled manner where the spliceosome complex catalyzes intron removal, deposits exon-junction complexes (EJC) to mark sites of intron removal but also participates in nuclear retention of incompletely spliced pre-mRNAs. Quality control of incompletely spliced pre-mRNAs to prevent their translation into aberrant proteins involves at least two mechanisms; the nuclear degradation of pre-mRNAs that failed to be exported to the cytoplasm, and the cytoplasmic degradation through nonsense-mediated decay (NMD) of intron-retaining RNAs with a premature stop codon 5' of an EJC [26].

The major spliceosome comprises 5 small nuclear RNAs (snRNA) and a multitude of associated protein factors to form small nuclear ribonucleoprotein particles (snRNPs), U1, U2, U4, U5, and U6 [27]. Spliceosome assembly occurs on pre-mRNAs through consensus sequences described in the preamble [2].

A minor spliceosome has been reported in plants, insects, and vertebrates, which is specialized in the splicing of a rare class of introns (less than $0.5 \%$ of all introns, which is still about 5000 introns as referred to Table 2) with unusual donor and branch signals and atypical and diverse terminal dinucleotides [28,29]. These introns are denoted U12-type introns as opposed to classical U2-type introns, as they use base-pairing of U12 at the branch point sequence instead of U2. Indeed, minor spliceosome uses an assembly of less abundant snRNPs, namely U11, U12, U4atac, and U6atac [28,29].

Thus, although they represent a minority of introns, highly evolutionary conserved U12-type introns are associated with a sophisticated parallel splicing system that is essential for cell division of vertebrates [30]. In addition to holding distinct functions, the possibility that this minor splicing pathway is spatially separated in the cell from the major pathway may well represent a mean through which eukaryotic cells extended their regulatory repertoire [30]. Indeed, there is still a debate about 
where the minor spliceosome operates, either in the cytoplasm [30] or in the nucleus [31], although evidence for the former accumulates:

(1) Transcripts with unspliced minor introns can be found in the cytoplasm, together with components of the minor spliceosome. In addition, the specific inhibition of minor spliceosome components in the cytoplasm, using antisense morpholino conjugated to a nuclear-export sequence, leads to accumulation of unspliced U12-introns in the cytoplasm [30].

(2) The minor spliceosome, unlike its major counterpart, seems to evade mitotic down-regulation, to be able to operate during mitosis and to function independently of transcription [30,32,33]. In a context when transcription and major splicing are down-regulated, while nuclear envelope breakdown releases potentially partially unspliced transcripts into the cytoplasm of the dividing cell, minor splicing could be available to control the fate of certain transcripts. The presence of a minor spliceosome is actually a distinguishing feature of species with open mitosis.

(3) Along the same lines, platelets, which are specialized hemostatic cells that circulate in the blood as anucleate cytoplasts, contain essential spliceosomal proteins and small nuclear ribonucleic acids (snRNAs), as well as a subset of pre-mRNAs that are further spliced into mature message in response to platelet activation [34]. This mechanism would allow platelets to respond to external signals triggered by vascular wall injury even in a context that is devoid of direct nuclear regulation.

(4) Additional support for the functionality of RNA splicing in the cytoplasm was provided in neurons. Neurons have a cell body containing the nucleus and core cytoplasmic components surrounded by highly specialized cytoplasmic extensions called dendrites and axons. Certain not fully spliced intron-retaining mRNAs are directed toward neuronal dendrites where they fully mature $[35,36]$. As mRNA can make hundreds of proteins on site, it is assumed that localized mRNA avoids the significant energy costs of moving protein molecules individually. Similarly, localized splicing like in dendrites of neurons, and presumably in other cell types, may serve as a regulatory switch to produce translatable mRNAs when and where the protein is needed.

(5) Cytoplasmic splicing is one of the major regulatory mechanisms of the unfolded protein response (UPR), although it occurs through unconventional mechanisms [37]. Splicing of X-box binding protein 1 (XBP1) and Homologous to Atf/Creb1 (HAC1) pre-mRNAs, regulators of the UPR, occurs in the cytoplasm using a kinase with endoribonuclease activity (IRE1) followed by joining of exons by an RNA ligase [37-40]. HAC1 mRNA is exported to the cytoplasm as an intron-retaining mRNA preventing complete translation of polyribosome-associated HAC1 mRNAs [37-40]. This mechanism provides a way to attenuate translation of the transcription factor Haclp in cells in which the UPR is not induced.

In sum, cytoplasmic splicing offers an efficient way to diversify cellular phenotypes without the need for nuclear activation of sets of genes as well as allowing for rapid regulation of local environment and subcellular proteomes and hence, for a quasi instant response to environmental cues.

\section{Splicing of Introns to Produce Small Non-Coding Transcripts}

miRNAs play pivotal roles in diverse biological functions, mainly through the repression of target genes. Less than half of intronic miRNAs are transcribed independently of their host gene, as long primary capped and polyadenylated transcripts (pri-miRNAs) by RNA polymerase II (RNA pol II), which 
undergo a series of maturation steps via the formation of a hairpin-forming precursor (pre-miRNA) until the production of mature miRNAs in the cytoplasm. These intronic miRNAs should be named intragenic or nested miRNAs to distinguish them from independent intergenic miRNAs. In contrast, the other half of so-called intronic miRNAs share promoter and regulatory elements with their host gene $[18,19,41-43]$. As a consequence, the pre-mRNA of the host gene also serves as the pri-miRNA that is processed as described above [44-46]. Some examples of intronic snoRNAs and miRNAs along with their host genes are described in Table 4.

Interestingly, there are cases where small regulatory RNAs are directly produced by way of splicing of the intron from the host transcript and thus, are strictly dependent on both transcription and splicing of the host gene.

In the case of snoRNAs, while some have their own promoter and are transcribed by RNA pol II, the majority is produced through splicing of the host intron. Whereas most of the host transcripts are mRNAs, some examples of long non-coding RNA (lncRNA) hosting snoRNAs exist such as the growth arrest-specific transcript 5 (GAS5) that contains 10 different snoRNAs, almost one in each one of its introns (all but the intron 9/11) [47]. Noteworthy, there is a class of genes called Small Nucleolar RNA Host Gene (SNHG) whose mRNAs produced after the maturation steps are degraded, the only stable isoforms generated by the splicing process being those retaining snoRNA-hosting introns [47]. There are 19 annotated SNHG genes in humans hosting 53 snoRNAs (from 1 to 15 snoRNA per gene; GRCh38).

At least two alternative pathways in the biogenesis of miRNAs use splicing to produce pre-miRNA-like transcripts independently of the microprocessor complex: the mirtron and the simtron pathways (Figure 4). 
Table 4. Some examples of intronic snoRNAs and miRNAs and their host genes.

\begin{tabular}{|c|c|c|c|c|c|c|}
\hline & Name & Genome Position & Host Intron & Host Gene & Genome Position & Gene Function \\
\hline \multirow{7}{*}{ snoRNA } & $A C A 67$ & $\begin{array}{c}\operatorname{chr} 21: 33,749,496- \\
33,749,631 \\
\end{array}$ & Intron 5 & $\begin{array}{l}\text { URB Ribosome Biogenesis } 1 \\
\text { homolog (URB1) }\end{array}$ & $\begin{array}{c}\operatorname{chr} 21: 33,683,330- \\
33,765,312 \\
\end{array}$ & Ribosome biogenesis \\
\hline & $H B I-43$ & $\begin{array}{c}\operatorname{chr} 20: 17,943,353- \\
17,943,589 \\
\end{array}$ & Intron 1 & Sorting Nexin 5 (SNX5) & $\begin{array}{c}\operatorname{chr} 20: 17,922,244- \\
17,949,490 \\
\end{array}$ & $\begin{array}{l}\text { Member of the sorting nexin family, involved in } \\
\text { intracellular trafficking }\end{array}$ \\
\hline & SNORD119 & $\begin{array}{c}\operatorname{chr} 20: 2,443,605- \\
2,443,686\end{array}$ & Intron 2 & $\begin{array}{l}\text { Small Nuclear Ribonucleoprotein } \\
\text { Polypeptides B and B1 (SNRPB) }\end{array}$ & $\begin{array}{c}\operatorname{chr} 20: 2,442,288- \\
2,451,499\end{array}$ & $\begin{array}{l}\text { Nuclear proteins that are found in common among U1, U2, U4/U6, and U5 small } \\
\text { ribonucleoprotein particles (snRNPs) }\end{array}$ \\
\hline & U101 & $\begin{array}{c}\text { chr6:133136446- } \\
133136518 \\
\end{array}$ & Intron 3 & Ribosomal protein S12 (RPS12) & $\begin{array}{c}\text { chr6:133,135,708- } \\
133,138,703\end{array}$ & Component of the ribosomal $40 \mathrm{~S}$ subunit \\
\hline & $H B I I-429$ & $\begin{array}{c}\text { chr6:133137941- } \\
133138016\end{array}$ & Intron 4 & Ribosomal protein S12 (RPS12) & $\begin{array}{c}\text { chr6:133,135,708- } \\
133,138,703 \\
\end{array}$ & Component of the ribosomal $40 \mathrm{~S}$ subunit \\
\hline & $A C A 33$ & $\begin{array}{c}\text { chr6:133138358- } \\
133138490 \\
\end{array}$ & Intron 5 & Ribosomal protein S12 (RPS12) & $\begin{array}{c}\text { chr6:133,135,708- } \\
133,138,703 \\
\end{array}$ & Component of the ribosomal $40 \mathrm{~S}$ subunit \\
\hline & $A C A 37$ & $\begin{array}{c}\operatorname{chr} 18: 51,748,654- \\
51,748,782 \\
\end{array}$ & Intron 1 & $\begin{array}{l}\text { Methyl-CpG Binding Domain } \\
\text { protein } 2 \text { (MBD2) }\end{array}$ & $\begin{array}{c}\operatorname{chr} 18: 51,677,971- \\
51,751,158 \\
\end{array}$ & Repress transcription from methylated gene promoters \\
\hline \multirow{7}{*}{ miRNA } & hsa-mir-643 & $\begin{array}{c}\operatorname{chr} 19: 52,785,050- \\
52,785,146 \\
\end{array}$ & Intron 1 & Zinc Finger protein 766 (ZNF766) & $\begin{array}{c}\operatorname{chr} 19: 52,772,824- \\
52,795,976 \\
\end{array}$ & Unknown \\
\hline & hsa-mir-220c & $\begin{array}{c}\text { chr19:49,063,529- } \\
49,063,611 \\
\end{array}$ & Intron 1 & $\begin{array}{l}\text { Sulfotransferase family, cytosolic, } \\
\text { 2B, member } 1 \text { (SULT2B1) }\end{array}$ & $\begin{array}{c}\operatorname{chr} 19: 49,055,429- \\
49,102,684 \\
\end{array}$ & $\begin{array}{l}\text { Catalyze the sulfate conjugation of many hormones, neurotransmitters, drugs, } \\
\text { and xenobiotic compounds }\end{array}$ \\
\hline & hsa-mir-3191 & $\begin{array}{c}\operatorname{chr} 19: 47,730,201- \\
47,730,276 \\
\end{array}$ & Intron 2 & BCL2 Binding Component 3 (BBC3) & $\begin{array}{c}\operatorname{chr} 19: 47,724,079- \\
47,736,023 \\
\end{array}$ & $\begin{array}{l}\text { Member of the BCL-2 family of proteins, cooperates with direct activator proteins to } \\
\text { induce mitochondrial outer membrane permeabilization and apoptosis }\end{array}$ \\
\hline & hsa-mir-770 & $\begin{array}{c}\operatorname{chr} 14: 101,318,727- \\
101,318,824 \\
\end{array}$ & Intron 9 & $\begin{array}{l}\text { Maternally Expressed } 3 \\
\text { (non-protein coding) (MEG3) }\end{array}$ & $\begin{array}{c}\operatorname{chr} 14: 101,292,445- \\
-101,327,360 \\
\end{array}$ & $\begin{array}{l}\text { Long ncRNA tumor suppressor. Interacts with the tumor suppressor p } 53 \text {, and regulates } \mathrm{p} 53 \\
\text { target gene expression }\end{array}$ \\
\hline & hsa-mir-1273d & $\begin{array}{c}\text { chr1:10287776- } \\
10287861 \\
\end{array}$ & Intron 1 & $\begin{array}{l}\text { Kinesin family member 1B } \\
\text { (KIF1B) }\end{array}$ & $\begin{array}{c}\operatorname{chr} 1: 10,270,764- \\
10,441,661 \\
\end{array}$ & Transports mitochondria and synaptic vesicle precursors \\
\hline & hsa-mir-3190 & $\begin{array}{c}\operatorname{chr} 19: 47,730,199- \\
47,730,278\end{array}$ & Intron 2 & $\begin{array}{l}\text { BCL2 Binding Component } 3 \\
\text { (BBC3) }\end{array}$ & $\begin{array}{c}\operatorname{chr} 19: 47,724,079- \\
47,736,023\end{array}$ & $\begin{array}{l}\text { Member of the BCL-2 family of proteins, cooperates with direct activator proteins to } \\
\text { induce mitochondrial outer membrane permeabilization and apoptosis }\end{array}$ \\
\hline & hsa-mir-942 & $\begin{array}{c}\operatorname{chr} 1: 117,637,265- \\
117,637,350 \\
\end{array}$ & Intron 18 & $\begin{array}{l}\text { Transcription Termination Factor, } \\
\text { RNA polymerase II (TTF2) }\end{array}$ & $\begin{array}{c}\operatorname{chr} 1: 117,602,949- \\
117,645,491 \\
\end{array}$ & Member of the SWI2/SNF2 family of proteins \\
\hline
\end{tabular}




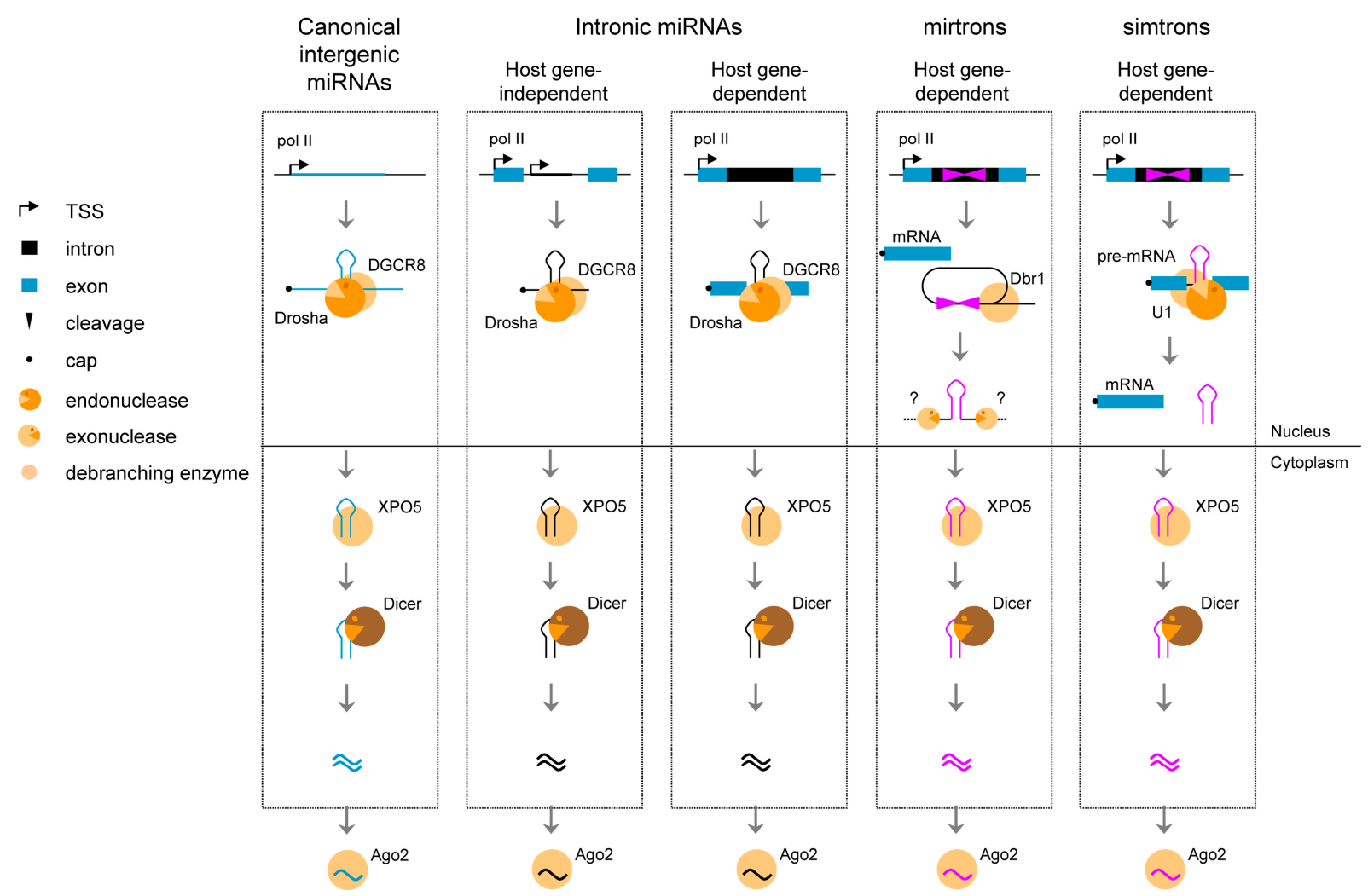

Figure 4. Different mechanisms of microRNA biogenesis. The first three panels correspond to the canonical miRNA pathway, either intergenic (miRNAs) or intronic (intronic miRNAs), and the last two panels represent new alternative pathways, either independent of the microprocessor Drosha/DGCR8 (mirtrons) or independent of DGCR8 but dependent of U1 snRNP (simtrons), both dependent on splicing to produce miRNAs. DGCR8 stands for DiGeorge syndrome critical region gene 8. Adapted from [48].

Unlike canonical miRNAs that require the microprocessor complex to produce the hairpin pre-miRNA, the so-called mirtron pathway is thought to require debranching of the lariat-intron produced by splicing, by a debranching enzyme dbr1, as a prerequisite to produce a hairpin pre-miRNA-like structure [49]. Until now, hundreds of mirtrons have been predicted through bioinformatical approaches although the mirtron origin, i.e., dependency on splicing and debranching machineries, has been experimentally validated for a handful of them [50]. More recently, another alternative pathway to generate miRNAs (simtrons) from introns has been described, which also relies on splicing factors such as U1 snRNP and on the microprocessor enzyme Drosha [51,52] but not on the debranching enzyme.

Embedding of genetic information for small regulatory RNAs within a longer mRNA or ncRNA provides an attractive concerted model for eukaryotic gene regulation, whereby multiple actors in the same pathways or in a given cellular context are produced from interdependent transcripts. The co-linear expression of miRNA and protein-coding genes may also function to ensure negative feedback on the protein-coding gene to prevent its over-expression. Indeed, while some intronic miRNAs are transcribed from their own promoter as independent transcription units, expression of intronic miRNAs has been widely linked to the regulation of expression of their host gene [43,53]. Furthermore, approximately $20 \%$ of intronic miRNAs (56 out of 296) have been predicted to target their own host transcript, either through recognition of the 3'-UTR, or indirectly through the transcriptional inhibition 
of a positive regulator of the host gene [54,55]. While there is growing evidence for a complex crosstalk between transcription, splicing and pre-miRNA processing and for a potential co-regulation of miRNA and host gene expression, this relationship is not yet completely understood [44,56,57].

Splicing of introns may also lead to the production of long non-coding RNAs with a circular structure (ciRNA). In human cells, Zhang and colleagues [58] have recently identified hundreds of such RNAs, ranging from 200 nt to over 3000 nt in length, with no ORF, and suggested to be expressed in a cell-specific manner. The mechanism of biogenesis was described as follows [58]; the lariat structure of introns that contain a consensus 7 nt GU-rich pattern in 5' splice site and an 11 nt C-rich element near the branchpoint are digested from the 3' end to the branchpoint to preserve the loop portion of the lariat intron. In contrast to circular RNAs originating from circularized exons and acting as miRNA sponges in the cytoplasm [59,60], intronic ciRNAs seem to function as positive regulators of Pol II transcription and play a role in the efficient transcription of their host gene.

\section{Introns Can Be Retained within Coding Segments-When Alternative Splicing of Introns Participates in Proteome Diversification}

Alternative splicing (AS) is a mechanism that allows the inclusion of non-coding sequences (introns) or excision of coding segments (exons) within mature mRNAs. While AS of introns represents a major event in plants, it accounts for only 2 to $5 \%$ of all alternative events in humans $[61,62]$. However, given the 252,243 introns in the human genome (Table 2), this could still contribute to the generation of additional 5044 to 12,612 potential protein isoforms. Actually, 6157 introns from the UCSC Table Brower (Alt Events-Alternative Splicing, Alternative Promoter and Similar Events in UCSC Genes) have been described to be conserved between human and mouse, and further confirmed to exist in EST or cDNA databases, indicating that they may well be included in mRNAs under certain physiological conditions [63]. As shown in Figure 5, introns subjected to AS are located predominantly in 5' of the genes (more than $20 \%$ are intron 1 ).

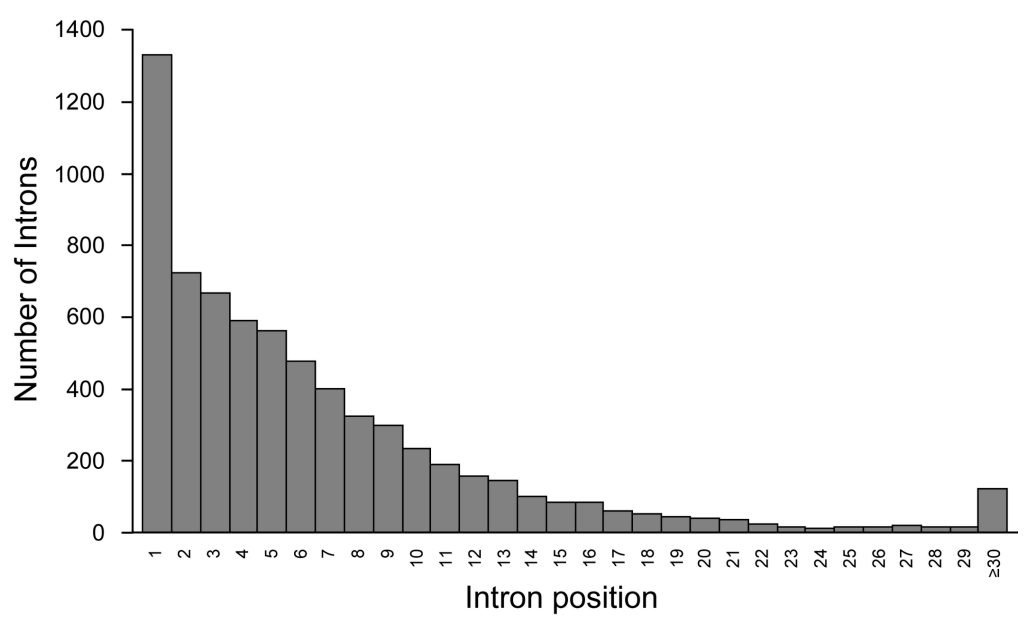

Figure 5. Intron distribution relative to their position in genes. About $20 \%$ of all introns subjected to alternative splicing (AS) are intron 1. 
We already mentioned examples where incompletely spliced intron-retaining transcripts are exported to the cytoplasm where their maturation is completed under certain physiological or cellular contexts. This may seem surprising since, in the majority of cases, intron retention leads to premature stop codons that trigger the cellular surveillance machinery and degradation of such transcripts by the nonsense-mediated decay pathway (NMD) [64]. Why and how some intron-retaining transcripts escape NMD has not been completely solved, but can include the presence of retrotransposon-containing sequences like intron-retaining transcripts in dendritic cells [65].

Besides the already mentioned example of intron-retention that allows for fine tuning of protein production at the right place and at the right moment in dendritic cells and neurons [35,36], intron retention also contributes to the control of tissue specific gene expression. For example, $L Y 6 G 5 B$ and LY6G6D genes located in the major histocompatibility complex (MHC) class III region on chromosome 6 can produce leukocyte antigen-6 (Ly6)-producing mRNA as well as intron-retaining non-coding transcripts that seem to be more abundant and stable than the correctly spliced isoform in most cell lines tested, and to escape NMD [66]. This mechanism was proposed to prevent production of LY6 antigens in non-affiliated tissues.

When it is tightly coupled to NMD, orchestrated intron retention allows for fine control of expression levels of proteins involved in the immune response [67]. It also allows for fine control of transcriptional output, through selective degradation via the NMD when intron retention leads to a premature stop codon or through nuclear retention that prevent their translation [68]. Other examples include transcriptional diversification through IR discussed in Section 8.

More directly, intron-retention participates in the diversification of the proteome, although, as we already mentioned, it is less commonly used in mammals than in plants. Figure 6 illustrates an attractive case of intron retention taking as an example carcino-embryonic antigen-related cell adhesion molecule 6 (CAECAM6) and a novel spliced variant CAECAM6-Long (CAECAM6-L) specifically expressed in rat testis, which both belong to an immunoglobulin (Ig) superfamily of proteins. The retention of intron 3 in the mature transcript not only adds an IgCAM (immunoglobulin superfamily cell adhesion molecule) domain, but also triggers a shift in the open reading frame leading to the subsequent choice of a more downstream stop codon. This shift adds the end of exons 5 to 7 to coding sequences, which in turn add two additional IgCAM domains. Therefore, Ceacam6 protein contains only one Ig-like domain without the transmembrane region whereas Ceacam6-L has three IgCAM domains and a transmembrane region. Thus, intron retention may add directly (exon 3) or indirectly (exons 5 to 7 ) three new protein domains conferring novel functions to an adhesion molecule in male germ cells [69].

Other examples of intron-retained transcript together with their biological function in mammals can be found in Table 1 of Buckley et al. [70]. 


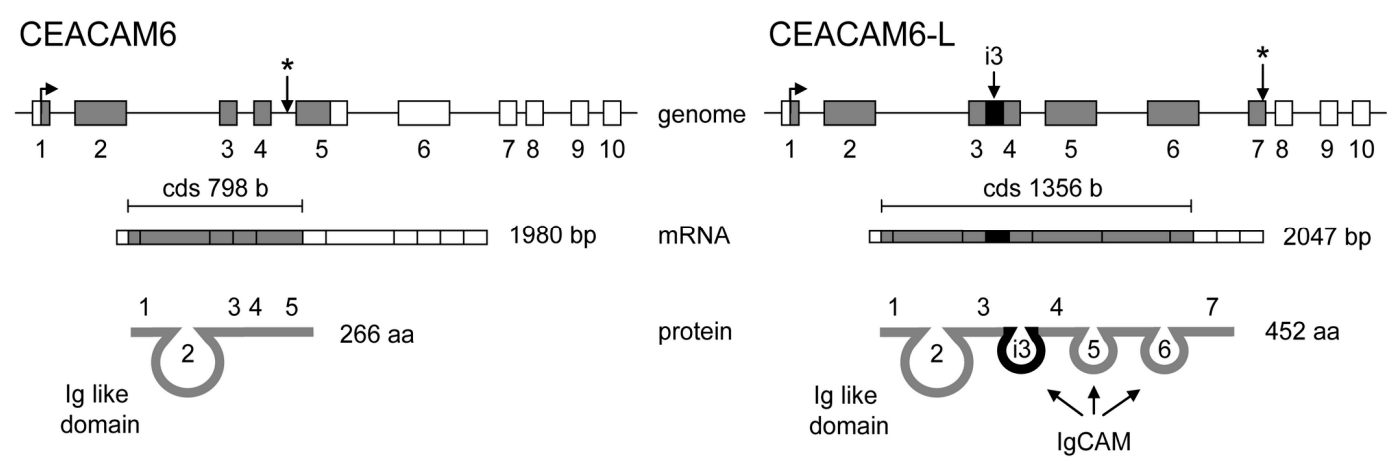

Figure 6. Carcino-embryonic antigen related cell adhesion molecule 6 (CAECAM6) and its novel spliced variant CAECAM6-Long (CAECAM6-L) from rat testis. Gene, mRNA and protein representation reproduced using data from [69]. Exons are numbered. Twisted arrow and star corresponded to ATG and stop codon, respectively. Intron 3 is denoted i3. Colored boxes corresponded to exons, thin line to introns except for i3, which was shown as a black box. White and grey boxes are for untranslated region (UTR) and coding sequences, respectively.

\section{Introns as a Switch to Produce Coding or Non-Coding RNAs-When Alternative Splicing of Introns Generates Transcriptome Diversity}

It is now evident that the transcriptional output of mammalian genomes is much more complex than estimates based on the number of protein-coding genes, and that non-coding RNA widely increase the source of regulatory molecules. We recently characterized a new class of ncRNAs, called bifunctional RNAs, i.e., RNAs for which both coding capacity and activity as functional RNA have been described [71-79].

Historically, the pioneer member of this new class of RNAs is SRA (Steroid Receptor RNA Activator). SRA was first identified as a structural ncRNA molecule in hormone receptor complexes, characterized by discrete stem-loop structures required for its function as a co-activator [80,81] as extensively reviewed by Cooper et al. [72]. A few years later, we identified new SRA isoforms, exhibiting an additional exon upstream of the core exons, containing two initiating methionines and a predicted open reading frame (ORF) of 236/224 amino acids, for which two associated SRA proteins (SRAP) were detected shortly afterwards [71,76,77,82,83]. Interestingly, the existence of both coding and non-coding SRA transcripts seems to be regulated, at least in part, by the differential splicing of the first intron of SRA [76,77]. Whereas all these isoforms exist in the cell, we reported that the balance between coding and non-coding isoforms influences the fate of human muscle progenitors towards self-renewal or differentiation [77,79] which is in total agreement with AS working as a developmental switch.

An example of such a genetic locus producing both coding and non-coding RNA, depending primarily on an event of AS of intron (Figure 7), is no longer a weird isolated case. First, we recently hypothesized that similar cases, not yet formally tested experimentally, might exist and revealed that the human genome contains around 300 possibilities of potentially new bifunctional RNA, i.e., in which intron retention disrupts the ORF permitting transcription of a ncRNA [78]. Specific examples can also be found in the literature, like the case of Apolipoprotein $\mathrm{E}$ (ApoE), a 
multifunctional protein with three common isoforms (ApoE2, ApoE3, and ApoE4) that play different roles in lipid metabolism and neurobiology. An additional isoform with intron 3 retention (ApoE-I3) has been described [84]. Whereas ApoE-I3 escapes degradation and is stably expressed as a nuclear-retained and non-translated transcript under normal conditions in neurons, a switch towards splicing of intron 3 and expression of the ApoE mRNA that is correctly exported to the cytoplasm and translated into a protein product occurs in response to neuronal injury [84]. More intriguingly, a splicing RNA isoform of the murine liver X receptor (LXR)- $\beta$ with retained intron 2 has been recently proposed to function as a co-activator of its LXR- $\beta$ protein counterpart [85]. Conversely, we found that SRA protein SRAP could act as an antagonist of the co-activation function of the non-coding SRA RNA on MyoD-mediated muscle differentiation and forced reprogramming [77,79]. Other examples exist throughout species, which have at least in common that intron-retaining transcripts escape surveillance machineries and that both coding and non-coding RNAs produced by a given genetic locus operate in the same pathways (reviewed in [79]).

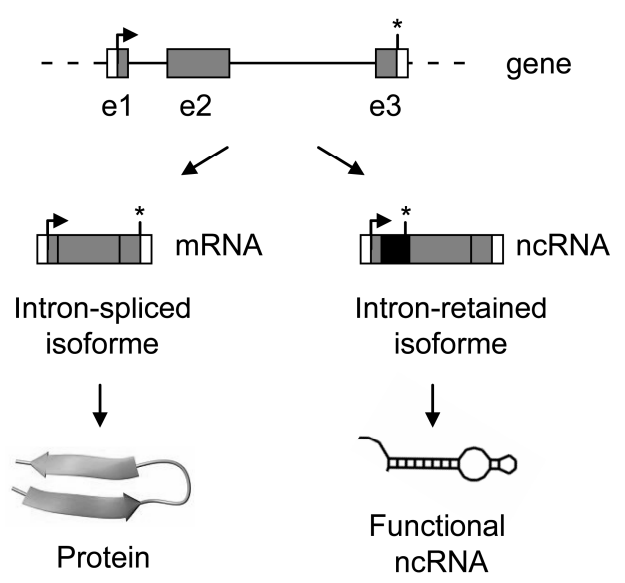

Figure 7. Both coding and non-coding RNAs can be produced by a given genetic locus. Intron-spliced isoforms are translated into protein while intron-retaining transcripts escape surveillance machineries and produce functional ncRNAs. Exons are numbered and represented by grey boxes and by thin lines. Arrow and star represent ATG and stop codon, respectively. In the mature transcript, the retained intron appears as a black box, UTR and coding sequences as white and grey boxes respectively.

Combined, the recent findings that alternative splicing of introns could produce RNAs with coding capacity or acting as functional ncRNAs and that splicing could directly generate small regulatory RNAs raise the fascinating assumption that a single transcription unit could generate multiple molecules including proteins, long or smaller regulatory ncRNAs such as miRNAs, and bring to light the central role of mammalian introns in the diversification of both proteome and transcriptome depending upon the need of the cell to respond to particular environmental settings.

\section{Concluding Remarks}

Introns have been regarded for a long time as "junk DNA" and remnants of archaic ancestral genomes. Questions about their origin and function arose immediately after their discovery in 1977, 
in particular regarding the energy waste that this represents for the cell to transcribe introns if they have to be eliminated from transcripts. Since then, accumulating evidence lent support to their fundamental importance in the regulation of mammalian gene expression programs, from transcriptional initiation, termination and stability, through recruitment of the exon-junction complex to recruitment of chromatin remodelers through the spliceosome.

With introns representing more than half of the genome in higher eukaryotes and being absent from prokaryotic genomes, the apparent correlation between the genomic fraction occupied by introns and organism complexity must have some functional significance.

In essence, eukaryotic cells use a variety of strategies to control their transcriptional output that employ a large number of regulatory factors that, in turn, must be tightly regulated. We provided examples whereby introns, as genetic entities or RNA segments, facilitate or participate in this amazing regulation feat by sheltering information for small regulatory RNAs allowing for concerted expression of multiple molecules in a given context, influencing where and when a messenger RNA is spliced and translated, preventing or attenuating translation off context or, on the contrary, diversifying the type and function of the molecules produced depending on the internal and external environment.

All these intron-linked mechanisms add some levels of sophistication in the way mammalian cells gain their phenotypic variability and opened a whole new field of investigation where introns take central stage and emerge as key elements in shaping cell identity.

\section{Acknowledgments}

Claire Francastel is supported by the Institut National de la Santé et de la Recherche Médicale (INSERM) and Florent Hubé is supported by the Centre National de la Recherche Scientifique (CNRS).

\section{Author Contributions}

Florent Hubé and Claire Francastel wrote the paper.

\section{Conflicts of Interest}

The authors declare no conflict of interest.

\section{References}

1. Rogozin, I.B.; Carmel, L.; Csuros, M.; Koonin, E.V. Origin and evolution of spliceosomal introns. Biol. Direct. 2012, 7, 1-28.

2. Zhang, M.Q. Statistical features of human exons and their flanking regions. Hum. Mol. Genet. 1998, 7, 919-932.

3. Abelson, J.; Trotta, C.R.; Li, H. tRNA splicing. J. Biol. Chem. 1998, 273, 12685-12688.

4. Cech, T.R. Ribozymes, the first 20 years. Biochem. Soc. Trans. 2002, 30, 1162-1166.

5. Koonin, E.V. The origin of introns and their role in eukaryogenesis: A compromise solution to the introns-early versus introns-late debate? Biol. Direct. 2006, 1, 1-22.

6. Hare, M.P.; Palumbi, S.R. High intron sequence conservation across three mammalian orders suggests functional constraints. Mol. Biol. Evol. 2003, 20, 969-978. 
7. Sasaki-Haraguchi, N.; Shimada, M.K.; Taniguchi, I.; Ohno, M.; Mayeda, A. Mechanistic insights into human pre-mRNA splicing of human ultra-short introns: Potential unusual mechanism identifies G-rich introns. Biochem. Biophys. Res. Commun. 2012, 423, 289-294.

8. Sakharkar, M.K.; Chow, V.T.; Ghosh, K.; Chaturvedi, I.; Lee, P.C.; Bagavathi, S.P.; Shapshak, P.; Subbiah, S.; Kangueane, P. Computational prediction of SEG (single exon gene) function in humans. Front Biosci. 2005, 10, 1382-1395.

9. Sakharkar, M.K.; Kangueane, P.; Petrov, D.A.; Kolaskar, A.S.; Subbiah, S. SEGE: A database on "intron less/single exonic" genes from eukaryotes. Bioinformatics 2002, 18, 1266-1267.

10. Sakharkar, M.K.; Kangueane, P. Genome SEGE: A database for "intronless" genes in eukaryotic genomes. BMC Bioinform. 2004, 5, 67.

11. Brosius, J. Genomes were forged by massive bombardments with retroelements and retrosequences. Genetica 1999, 107, 209-238.

12. Kumar, A. An overview of nested genes in eukaryotic genomes. Eukaryot. Cell 2009, 8, 1321-1329.

13. Lee, Y.C.; Chang, H.H. The evolution and functional significance of nested gene structures in Drosophila melanogaster. Genome Biol. Evol. 2013, 5, 1978-1985.

14. Yu, P.; Ma, D.; Xu, M. Nested genes in the human genome. Genomics 2005, 86, 414-422.

15. Mattick, J.S.; Makunin, I.V. Small regulatory RNAs in mammals. Hum. Mol. Genet. 2005, 14, R121-R132.

16. Penny, D.; Hoeppner, M.P.; Poole, A.M.; Jeffares, D.C. An overview of the introns-first theory. J. Mol. Evol. 2009, 69, 527-540.

17. Westholm, J.O.; Lai, E.C. Mirtrons: microRNA biogenesis via splicing. Biochimie 2011, 93, 1897-1904.

18. Monteys, A.M.; Spengler, R.M.; Wan, J.; Tecedor, L.; Lennox, K.A.; Xing, Y.; Davidson, B.L. Structure and activity of putative intronic miRNA promoters. RNA 2010, 16, 495-505.

19. Ozsolak, F.; Poling, L.L.; Wang, Z.; Liu, H.; Liu, X.S.; Roeder, R.G.; Zhang, X.; Song, J.S.; Fisher, D.E. Chromatin structure analyses identify miRNA promoters. Genes Dev. 2008, 22, 3172-3183.

20. Braunschweig, U.; Gueroussov, S.; Plocik, A.M.; Graveley, B.R.; Blencowe, B.J. Dynamic integration of splicing within gene regulatory pathways. Cell 2013, 152, 1252-1269.

21. Burnette, J.M.; Miyamoto-Sato, E.; Schaub, M.A.; Conklin, J.; Lopez, A.J. Subdivision of large introns in Drosophila by recursive splicing at nonexonic elements. Genetics 2005, 170, 661-674.

22. Hatton, A.R.; Subramaniam, V.; Lopez, A.J. Generation of alternative Ultrabithorax isoforms and stepwise removal of a large intron by resplicing at exon-exon junctions. Mol. Cell 1998, 2, 787-796.

23. Ott, S.; Tamada, Y.; Bannai, H.; Nakai, K.; Miyano, S. Intrasplicing-Analysis of long intron sequences. Pac. Symp. Biocomput. 2003, 339-350.

24. Suzuki, H.; Kameyama, T.; Ohe, K.; Tsukahara, T.; Mayeda, A. Nested introns in an intron: Evidence of multi-step splicing in a large intron of the human dystrophin pre-mRNA. FEBS Lett. 2013, 587, 555-561.

25. Parra, M.K.; Gallagher, T.L.; Amacher, S.L.; Mohandas, N.; Conboy, J.G. Deep intron elements mediate nested splicing events at consecutive AG dinucleotides to regulate alternative 3 ' splice site choice in vertebrate 4.1 genes. Mol. Cell Biol. 2012, 32, 2044-2053. 
26. Brogna, S.; Wen, J. Nonsense-mediated mRNA decay (NMD) mechanisms. Nat. Struct. Mol. Biol. 2009, 16, 107-113.

27. Jurica, M.S.; Moore, M.J. Pre-mRNA splicing: Awash in a sea of proteins. Mol. Cell 2003, 12, 5-14.

28. Turunen, J.J.; Niemela, E.H.; Verma, B.; Frilander, M.J. The significant other: Splicing by the minor spliceosome. Wiley Interdiscip. Rev. RNA 2013, 4, 61-76.

29. Levine, A.; Durbin, R. A computational scan for U12-dependent introns in the human genome sequence. Nucleic Acids Res. 2001, 29, 4006-4013.

30. Konig, H.; Matter, N.; Bader, R.; Thiele, W.; Muller, F. Splicing segregation: The minor spliceosome acts outside the nucleus and controls cell proliferation. Cell 2007, 131, 718-729.

31. Pessa, H.K.; Will, C.L.; Meng, X.; Schneider, C.; Watkins, N.J.; Perala, N.; Nymark, M.; Turunen, J.J.; Luhrmann, R.; Frilander, M.J. Minor spliceosome components are predominantly localized in the nucleus. Proc. Natl. Acad. Sci. USA 2008, 105, 8655-8660.

32. Blanco, F.J.; Bernabeu, C. Alternative splicing factor or splicing factor-2 plays a key role in intron retention of the endoglin gene during endothelial senescence. Aging Cell 2011, 10, 896-907.

33. Caceres, J.F.; Misteli, T. Division of labor: Minor splicing in the cytoplasm. Cell 2007, 131, 645-647.

34. Denis, M.M.; Tolley, N.D.; Bunting, M.; Schwertz, H.; Jiang, H.; Lindemann, S.; Yost, C.C.; Rubner, F.J.; Albertine, K.H.; Swoboda, K.J.; et al. Escaping the nuclear confines: Signal-dependent pre-mRNA splicing in anucleate platelets. Cell 2005, 122, 379-391.

35. Racca, C.; Gardiol, A.; Eom, T.; Ule, J.; Triller, A.; Darnell, R.B. The neuronal splicing factor nova co-localizes with target RNAs in the dendrite. Front. Neural Circuits 2010, 4, 5.

36. Glanzer, J.; Miyashiro, K.Y.; Sul, J.Y.; Barrett, L.; Belt, B.; Haydon, P.; Eberwine, J. RNA splicing capability of live neuronal dendrites. Proc. Natl. Acad. Sci. USA 2005, 102, 16859-16864.

37. Yoshida, H. Unconventional splicing of XBP-1 mRNA in the unfolded protein response. Antioxid. Redox Signal. 2007, 9, 2323-2333.

38. Back, S.H.; Lee, K.; Vink, E.; Kaufman, R.J. Cytoplasmic IRE1 $\alpha$-mediated XBP1 mRNA splicing in the absence of nuclear processing and endoplasmic reticulum stress. J. Biol. Chem. 2006, 281, 18691-18706.

39. Ruegsegger, U.; Leber, J.H.; Walter, P. Block of HAC1 mRNA translation by long-range base pairing is released by cytoplasmic splicing upon induction of the unfolded protein response. Cell 2001, 107, 103-114.

40. Chapman, R.E.; Walter, P. Translational attenuation mediated by an mRNA intron. Curr. Biol. 1997, 7, 850-859.

41. Bartel, D.P. MicroRNAs: Genomics, biogenesis, mechanism, and function. Cell 2004, 116, 281-297.

42. Chien, C.H.; Sun, Y.M.; Chang, W.C.; Chiang-Hsieh, P.Y.; Lee, T.Y.; Tsai, W.C.; Horng, J.T.; Tsou, A.P.; Huang, H.D. Identifying transcriptional start sites of human microRNAs based on high-throughput sequencing data. Nucleic Acids Res. 2011, 39, 9345-9356.

43. Corcoran, D.L.; Pandit, K.V.; Gordon, B.; Bhattacharjee, A.; Kaminski, N.; Benos, P.V. Features of mammalian microRNA promoters emerge from polymerase II chromatin immunoprecipitation data. PLoS One 2009, 4, e5279.

44. Ramalingam, P.; Palanichamy, J.K.; Singh, A.; Das, P.; Bhagat, M.; Kassab, M.A.; Sinha, S.; Chattopadhyay, P. Biogenesis of intronic miRNAs located in clusters by independent transcription and alternative splicing. RNA 2014, 20, 76-87. 
45. Kim, Y.K.; Kim, V.N. Processing of intronic microRNAs. EMBO J. 2007, 26, 775-783.

46. Lee, Y.; Kim, M.; Han, J.; Yeom, K.H.; Lee, S.; Baek, S.H.; Kim, V.N. MicroRNA genes are transcribed by RNA polymerase II. EMBO J. 2004, 23, 4051-4060.

47. Smith, C.M.; Steitz, J.A. Classification of gas5 as a multi-small-nucleolar-RNA (snoRNA) host gene and a member of the 5'-terminal oligopyrimidine gene family reveals common features of snoRNA host genes. Mol. Cell Biol. 1998, 18, 6897-6909.

48. Falaleeva, M.; Stamm, S. Processing of snoRNAs as a new source of regulatory non-coding RNAs: SnoRNA fragments form a new class of functional RNAs. Bioessays 2013, 35, 46-54.

49. Ruby, J.G.; Jan, C.H.; Bartel, D.P. Intronic microRNA precursors that bypass Drosha processing. Nature 2007, 448, 83-86.

50. Ladewig, E.; Okamura, K.; Flynt, A.S.; Westholm, J.O.; Lai, E.C. Discovery of hundreds of mirtrons in mouse and human small RNA data. Genome Res. 2012, 22, 1634-1645.

51. Janas, M.M.; Khaled, M.; Schubert, S.; Bernstein, J.G.; Golan, D.; Veguilla, R.A.; Fisher, D.E.; Shomron, N.; Levy, C.; Novina, C.D. Feed-Forward microprocessing and splicing activities at a microRNA-containing intron. PLoS Genet. 2011, 7, e1002330.

52. Havens, M.A.; Reich, A.A.; Duelli, D.M.; Hastings, M.L. Biogenesis of mammalian microRNAs by a non-canonical processing pathway. Nucleic Acids Res. 2012, 40, 4626-4640.

53. Wang, D.; Lu, M.; Miao, J.; Li, T.; Wang, E.; Cui, Q. Cepred: Predicting the co-expression patterns of the human intronic microRNAs with their host genes. PLoS One 2009, 4, e4421.

54. Han, J.; Denli, A.M.; Gage, F.H. The enemy within: Intronic miR-26b represses its host gene, ctdsp2, to regulate neurogenesis. Genes Dev. 2012, 26, 6-10.

55. Hinske, L.C.; Galante, P.A.; Kuo, W.P.; Ohno-Machado, L. A potential role for intragenic miRNAs on their hosts' interactome. BMC Genomics 2010, 11, 533.

56. Havens, M.A.; Reich, A.A.; Hastings, M.L. Drosha promotes splicing of a pre-microRNA-like alternative exon. PLoS Genet. 2014, 10, e1004312.

57. Granat-Tamir, L.; Shomron, N.; Sperling, J.; Sperling, R. Interplay between pre-mRNA splicing and microRNA biogenesis within the supraspliceosome. Nucleic Acids Res. 2014, 42, 4640-4651.

58. Zhang, Y.; Zhang, X.O.; Chen, T.; Xiang, J.F.; Yin, Q.F.; Xing, Y.H.; Zhu, S.; Yang, L.; Chen, L.L. Circular intronic long noncoding RNAs. Mol. Cell 2013, 51, 792-806.

59. Guo, J.U.; Agarwal, V.; Guo, H.; Bartel, D.P. Expanded identification and characterization of mammalian circular RNAs. Genome Biol. 2014, 15, 409.

60. Hansen, T.B.; Jensen, T.I.; Clausen, B.H.; Bramsen, J.B.; Finsen, B.; Damgaard, C.K.; Kjems, J. Natural RNA circles function as efficient microRNA sponges. Nature 2013, 495, 384-388.

61. Pheasant, M.; Mattick, J.S. Raising the estimate of functional human sequences. Genome Res. 2007, 17, 1245-1253.

62. Ast, G. The alternative genome. Sci. Am. 2005, 292, 40-47.

63. Sugnet, C.W.; Kent, W.J.; Ares, M., Jr.; Haussler, D. Transcriptome and genome conservation of alternative splicing events in humans and mice. Pac. Symp. Biocomput. 2004, 9, 66-77.

64. De Lima Morais, D.A.; Harrison, P.M. Large-scale evidence for conservation of NMD candidature across mammals. PLoS One 2010, 5, e11695. 
65. Buckley, P.T.; Lee, M.T.; Sul, J.Y.; Miyashiro, K.Y.; Bell, T.J.; Fisher, S.A.; Kim, J.; Eberwine, J. Cytoplasmic intron sequence-retaining transcripts can be dendritically targeted via ID element retrotransposons. Neuron 2011, 69, 877-884.

66. Calvanese, V.; Mallya, M.; Campbell, R.D.; Aguado, B. Regulation of expression of two LY-6 family genes by intron retention and transcription induced chimerism. BMC Mol. Biol. 2008, 9, 81.

67. Wong, J.J.; Ritchie, W.; Ebner, O.A.; Selbach, M.; Wong, J.W.; Huang, Y.; Gao, D.; Pinello, N.; Gonzalez, M.; Baidya, K.; et al. Orchestrated intron retention regulates normal granulocyte differentiation. Cell 2013, 154, 583-595.

68. Braunschweig, U.; Barbosa-Morais, N.L.; Pan, Q.; Nachman, E.N.; Alipanahi, B.; Gonatopoulos-Pournatzis, T.; Frey, B.; Irimia, M.; Blencowe, B.J. Widespread intron retention in mammals functionally tunes transcriptomes. Genome Res. 2014, 24, 1774-1786.

69. Kurio, H.; Murayama, E.; Kaneko, T.; Shibata, Y.; Inai, T.; Iida, H. Intron retention generates a novel isoform of CEACAM6 that may act as an adhesion molecule in the ectoplasmic specialization structures between spermatids and sertoli cells in rat testis. Biol. Reprod. 2008, 79, 1062-1073.

70. Buckley, P.T.; Khaladkar, M.; Kim, J.; Eberwine, J. Cytoplasmic intron retention, function, splicing, and the sentinel RNA hypothesis. Wiley Interdiscip. Rev. RNA 2014, 5, 223-230.

71. Chooniedass-Kothari, S.; Emberley, E.; Hamedani, M.K.; Troup, S.; Wang, X.; Czosnek, A.; Hube, F.; Mutawe, M.; Watson, P.H.; Leygue, E. The steroid receptor RNA activator is the first functional RNA encoding a protein. FEBS Lett. 2004, 566, 43-47.

72. Cooper, C.; Vincett, D.; Yan, Y.; Hamedani, M.K.; Myal, Y.; Leygue, E. Steroid receptor RNA activator bi-faceted genetic system: Heads or Tails? Biochimie 2011, 93, 1973-1980.

73. Dinger, M.E.; Pang, K.C.; Mercer, T.R.; Mattick, J.S. Differentiating protein-coding and noncoding RNA: Challenges and ambiguities. PLoS Comput. Biol. 2008, 4, e1000176.

74. Dinger, M.E.; Gascoigne, D.K.; Mattick, J.S. The evolution of RNAs with multiple functions. Biochimie 2011, 93, 2013-2018.

75. Francastel, C.; Hube, F. Coding or non-coding: Need they be exclusive? Biochimie 2011, 93, 6-7.

76. Hube, F.; Guo, J.; Chooniedass-Kothari, S.; Cooper, C.; Hamedani, M.K.; Dibrov, A.A.; Blanchard, A.A.; Wang, X.; Deng, G.; Myal, Y.; et al. Alternative splicing of the first intron of the steroid receptor RNA activator (SRA) participates in the generation of coding and noncoding RNA isoforms in breast cancer cell lines. DNA Cell Biol. 2006, 25, 418-428.

77. Hube, F.; Velasco, G.; Rollin, J.; Furling, D.; Francastel, C. Steroid receptor RNA activator protein binds to and counteracts SRA RNA-mediated activation of MyoD and muscle differentiation. Nucleic Acids Res. 2011, 39, 513-525.

78. Ulveling, D.; Francastel, C.; Hube, F. Identification of potentially new bifunctional RNA based on genome-wide data-mining of alternative splicing events. Biochimie 2011, 93, 2024-2027.

79. Ulveling, D.; Francastel, C.; Hube, F. When one is better than two: RNA with dual functions. Biochimie 2011, 93, 633-644.

80. Lanz, R.B.; McKenna, N.J.; Onate, S.A.; Albrecht, U.; Wong, J.; Tsai, S.Y.; Tsai, M.J.; O'Malley, B.W. A steroid receptor coactivator, SRA, functions as an RNA and is present in an SRC-1 complex. Cell 1999, 97, 17-27. 
81. Lanz, R.B.; Razani, B.; Goldberg, A.D.; O’Malley, B.W. Distinct RNA motifs are important for coactivation of steroid hormone receptors by steroid receptor RNA activator (SRA). Proc. Natl. Acad. Sci. USA 2002, 99, 16081-16086.

82. Cooper, C.; Guo, J.; Yan, Y.; Chooniedass-Kothari, S.; Hube, F.; Hamedani, M.K.; Murphy, L.C.; Myal, Y.; Leygue, E. Increasing the relative expression of endogenous non-coding Steroid Receptor RNA Activator (SRA) in human breast cancer cells using modified oligonucleotides. Nucleic Acids Res. 2009, 37, 4518-4531.

83. Emberley, E.; Huang, G.J.; Hamedani, M.K.; Czosnek, A.; Ali, D.; Grolla, A.; Lu, B.; Watson, P.H.; Murphy, L.C.; Leygue, E. Identification of new human coding steroid receptor RNA activator isoforms. Biochem. Biophys. Res. Commun. 2003, 301, 509-515.

84. Xu, Q.; Walker, D.; Bernardo, A.; Brodbeck, J.; Balestra, M.E.; Huang, Y. Intron-3 retention/splicing controls neuronal expression of apolipoprotein E in the CNS. J. Neurosci. 2008, $28,1452-1459$.

85. Hashimoto, K.; Ishida, E.; Matsumoto, S.; Shibusawa, N.; Okada, S.; Monden, T.; Satoh, T.; Yamada, M.; Mori, M. A liver X receptor (LXR)- $\beta$ alternative splicing variant (LXRBSV) acts as an RNA co-activator of LXR- $\beta$. Biochem. Biophys. Res. Commun. 2009, 390, 1260-1265.

(C) 2015 by the authors; licensee MDPI, Basel, Switzerland. This article is an open access article distributed under the terms and conditions of the Creative Commons Attribution license (http://creativecommons.org/licenses/by/4.0/). 